\title{
Technology, business model, and market design adaptation toward smart electricity distribution: Insights for policy making
}

\author{
Guillermo Ivan Pereira ${ }^{\text {a }}{ }^{*}$, Jan Martin Specht ${ }^{\mathrm{d}}$, Patrícia Pereira da Silva ${ }^{\mathrm{ab}}$ and Reinhard Madlener $^{\mathrm{d}}$ \\ ${ }^{a}$ Energy for Sustainability Initiative \\ MIT Portugal Program, Faculty of Sciences and Technology, University of Coimbra \\ Rua Luís Reis dos Santos, Pólo II, 3030-788, Coimbra, Portugal \\ gpereira@student.dem.uc.pt \\ ${ }^{\mathrm{b}}$ Center for Business and Economics Research, Faculty of Economics, University of Coimbra. \\ Av. Dias da Silva, 165, 3004-512, Coimbra, Portugal \\ patsilva@fe.uc.pt \\ ${ }^{c}$ INESC Coimbra, Institute for Systems Engineering and Computers at Coimbra \\ Rua Sílvio Lima, Pólo II, 3030-290, Coimbra, Portugal \\ ${ }^{\mathrm{d}}$ Institute for Future Energy Consumer Needs and Behavior (FCN) \\ School of Business and Economics / E.ON Energy Research Center, RWTH Aachen University \\ Mathieustraße 10, 52074 Aachen, Germany \\ MSpecht@eonerc.rwth-aachen.de, RMadlener@eonerc.rwth-aachen.de
}

*Corresponding Author: Guillermo Ivan Pereira, gpereira@student.dem.uc.pt. 


\title{
Technology, business model, and market design adaptation toward smart electricity distribution: Insights for policy making
}

\begin{abstract}
The transformation of the electricity sector towards a sustainable energy supply and use has a disruptive potential for infrastructure and utilities. The spread of digital technologies, renewable energy, and prosumers requires a swift and well-guided adaptation of the electricity distribution industry to smart grid technologies and related business models. This paper, based on the large technical systems (LTS) conceptual framework, investigates the complex evolution and company and market design adaptation needs. Challenges and opportunities are analyzed through nine multi-stakeholder workshops, held in two EU member states (Germany and Portugal) in 2016-2017, engaging distribution system operators, researchers, academics, and integrated utility companies. The results indicate considerable uncertainty for DSOs regarding the value of large-scale smart meter rollouts. Also, a corporate culture with resistance to change is observed, challenging the integration of novel technologies and processes. Traditional regulation is seen as a barrier to smart grid investments, and is associated with job losses and knowled ge destruction. Policy-makers can benefit from these insights on the dynamics of DSOs, which can contribute to public policy design and market reform which traditionally has often been mainly concerned about operational efficiency in a steady-state, stable economy.
\end{abstract}

\section{Keywords}

Electricity distribution; smart grid; technology; business model; market design; policy. 


\section{Introduction}

The transition towards a low-carbon energy sector is currently a priority in most countries, recently reinforced through the Paris agreement signed in 2015 at the COP 21. Many European countries have set targets for the share of renewable energy: Germany, for example, aims to reach a share of $35 \%$ renewable energy by 2020, while Denmark and Sweden have set 50\% as a target (Anaya and Pollitt, 2015). Commonly envisioned transition paths include the integration of the heating and mobility sector into the electricity sector on the consumption side (sector coupling). The generation of electricity is expected to gradually shift from centralized thermal power plants to distributed energy resources (DER), which either feature high energy efficiency levels, due to combined heat and power generation, or are based on renewable energies, and thus carbon-free during operation, such as wind turbines and solar photovoltaic modules (Castro and Dantas, 2017; Palensky and Dietrich, 2011; Pereira and Silva, 2017).

Smart grids will play a key role in integrating these distributed energy resources and their associated flexibilities, increase energy and economic efficiency, and empower customers (European Commission, 2012), which is why the European Union (EU) prompted its member states to ensure the rollout of intelligent metering systems (European Commission, 2009a). These developments can be expected to strongly impact electricity distribution system operators (DSOs) their grid operations and the role of network infrastructures in the future (Lavrijssen et al., 2016; Pereira et al., 2018a).

While there has been some general discussion on challenges and opportunities for DSOs in a smart grid future (BMWi, 2014; Droste-Franke et al., 2012; Lavrijssen et al., 2016; Siano, 2014), few insights on recent developments and on how DSOs face this transition can be 
found in the literature (Pereira et al., 2018b). This research aims to contribute to a more detailed understanding of the ongoing sociotechnical transition dynamics impacting the electricity distribution industry in the European Union. The research design implemented in this study frames the distribution industry adaptation dynamics as a changing Large Technical System (LTS). Implementing the LTS conceptual framework in this regard proves particularly useful as its initial conceptualizations were derived from the appearance and evolution of electricity networks between 1880 and 1930 (Hughes, 1983). Now, one century later, the analysis of the complex processes underpinning the power sector, and the changing role of distribution infrastructure, are yet again critical. Particularly for electricity distribution, technological innovations, including distributed generation, electricity storage and demand response, supported by public policy agendas with ambitious decarbonization, decentralization, and digitalization goals; and changing consumer profiles are pressuring stable, and reliable distribution systems. In this context it becomes relevant to dedicate efforts for understanding this adaptation process, for Hughes:

"the effort to explain the change involves the consideration of many fields of human activity, including the technical, the scientific, the economic, the political, and the organizational. This is because power systems are cultural artifacts." (Hughes, 1983,p. 2).

As a result of this approach, this paper presents empirical insights on the challenges and opportunities that the sociotechnical transition towards smart grids and distributed energy resources represent for DSOs, and for the transformation of the electricity distribution industry in the European Union. The analysis conducted encompasses technology, business model, and market design aspects, for existing contributions in the literature often focus on the specificities of a single dimension. By doing so, we aim at providing a complementary perspective to the following areas of action focused on the electricity distribution industry 
adaptation dynamics. Firstly, the growing discussion focusing on the regulatory models to be applied on DSOs in the future (ACER and CEER, 2017; CEER, 2015, 2014), as well as the ongoing discussion on the most adequate electricity market design for the EU as part of the Clean Energy for All Europeans policy proposals (Council of the European Union, 2017a, 2017b, 2017c; European Commission, 2016a). Secondly, the efforts in understanding the role of smart grid and distributed generation technologies in a changing electricity system and the opportunities and benefits these represent (Gangale et al., 2017; Giordano et al., 2013, 2011; Giordano and Fulli, 2011; Hall and Foxon, 2014; Krishnamurti et al., 2012; Ruiz-Romero et al., 2014). Lastly, the importance of identifying the most adequate business model innovation approach and capabilities needed to realize the added value possible from new technologies and enabling policies (Helms, 2016; Nisar et al., 2013; Reuver et al., 2016; Shomali and Pinkse, 2016).

The findings presented result from a series of nine multi-stakeholder workshops, conducted in 2016 and 2017, engaging experts in the field, in Germany and Portugal, as two representative EU member countries. Participating stakeholders include experts from research, academia, and industry exposed to both the national and European context on the energy transition. This research was developed within the scope of the project "The Electricity Sector Transition - Transnational Experiences from DSOs and Cooperatives" jointly developed by the Energy for Sustainability Initiative (EfS), University of Coimbra, Portugal, and the Institute for Future Energy Consumer Needs and Behavior (FCN) at the E.ON Energy Research Center, RWTH Aachen University, Aachen, Germany.

The remainder of this paper is organized as follows. Section 2 provides background information on the large technical systems conceptual framework, and on the business model, 
legislative aspects, and technology developments that influence DSOs. Section 3 describes the research design, after which section 4 presents and discusses the findings. Finally, section 5 summarizes the main challenges and opportunities identified, whereas section 6 draws conclusions and provides policy implications and recommendations.

\section{Background}

\subsection{Large technical systems conceptual framework}

Large Technical Systems (LTS) encompass a complex network of assets and technologies, organizations, and legislative elements, implemented to deliver critical services to society (Bijker et al., 2012; Ewertsson and Ingelstam, 2004; Hughes, 1987). As a conceptual framework of analysis it focuses on achieving a greater understanding on the interaction and evolution of its elements, aiming at delivering an integrated view for a better understanding of its complex evolution and adaptation (Davies, 1996). In LTS, adaptation and development are driven by the occurrence of reverse salients and critical problems. A reverse salient occurs when an existing or new component operates out of sync with the overall system elements. In the case of electricity distribution, for instance, the growing diffusion of small-scale distributed generation from solar PV and wind technologies represent such reverse salients, challenging the traditional operation of the networks and the regulatory and business operations traditionally in place. Acting upon reverse salients and the challenges they create for the system is what enables transitions in LTS.

The transition-oriented conceptual foundations of LTS have led to two noteworthy streams of knowledge development. Firstly, its direct applications for the understanding of changes in large technical system-based ind ustries, such as energy networks (Bolton and Foxon, 2015; Hasenöhrl, 2018; Markard and Truffer, 2006; Palm and Gustafsson, 2018), water 
infrastructure (Dobre et al., 2018), and telecommunication, food, and transportation (Davies, 1996; Vleuten, 2018), to name just a few. Secondly, its contribution to the evolving field of enquiry on socio-technical sustainability transitions (Farla et al., 2012), and its specific analytical approaches such as the Multi-Level Perspective (MLP) (Geels, 2002; Rip and Kemp, 1998), and the Triple Embeddedness Framework (TEF) (Geels, 2014), which have been used to design policy for low-carbon development across technologies, firms, industries, and regions.

Furthermore, the relevance of LTS as a conceptual framework has been recently reinforced given its ability to facilitate the understanding not only of the systems' development and growth, but also of reconfiguration in mature systems, as is the case of electricity distribution (Sovacool et al., 2018). Understanding the recent adaptation dynamics towards a smart and sustainable electricity distribution industry in the EU benefits from this conceptual approach, as its original aim was specifically to study infrastructure-based, capital intensive industries (Truffer et al., 2010). Considering this, the LTS conceptual framework provides a sensible approach for understanding the sociotechnical transitions in electricity distribution, particularly the changing roles and responsibilities of electricity distribution system operators (DSOs). Therefore, it enables to develop insights for policy making that consider business model, legislative, and technological challenges, and opportunities.

\subsection{The business model of incumbent DSOs}

For the EU, 'distribution system operator' means a natural or legal person responsible for operating, ensuring the maintenance of and, if necessary, developing the distribution system in a given area and, where applicable, its interconnections with other systems and for ensuring the long-term ability of the system to meet reasonable demands for the distribution 
of electricity. (European Commission, 2009a). For this service of general economic interest, DSOs are remunerated through a regulated tariff. While this description might sum up the incumbent role of DSOs in the past quite well, it falls short when it comes to the recent developments in the context of the energy transition.

The traditional, asset-focused task of operating, maintaining, and developing distribution grid assets already extends to the operation of smart metering devices, with the DSO becoming a data hub operator (Eurelectric, 2010). The diffusion of distributed generation and storage assets as well as the coupling of the heat and the mobility sector result in the problem that private households can be less and less represented by standard load profiles, which increases the importance of having more detailed information on local grids. Furthermore, the historical hardware solutions to grid shortages focused on grid expansion can be complemented by operational solutions such as flexibility management.

Another aspect not considered in the traditional definition of a DSO is the degree of supplyside concentration, where significant differences exist across Europe. Germany, for example, at about 880 DSOs, is on top of the list among the EU member countries, whereas countries such as Ireland, Portugal or Lithuania have a single or dominant DSO (Eurelectric, 2013; Prettico et al., 2016). Despite these regional idiosyncrasies, all Member States are subject to EU legislation and also to the transition from natural monopolistic markets with vertically integrated companies to liberalized markets and unbundling, both of which are outlined next.

\subsection{Market design, legislation and regulation of European grids}

The European Commission (EC) set security of energy supply, sustainability, and competitiveness as the main goals for the energy market (European Commission, 2015, 2010). The introduction of competition was identified as a key element for achieving these 
and was gradually implemented through the EC energy packages (1996, 2003, and 2009) that pushed for the liberalization of the electricity market and the unbundling of the vertically integrated electric utilities (European Commission, 2016b; Ringel and Knodt, 2018). These policies were transposed to national law in most EU countries, which is why the operation of electric grids can today be seen as an independent business that may largely exclude other activities in the fields of electricity generation or retailing (exceptions for small operators with less than 100,000 customers exist, cf. European Commission (2009a).

A second important aspect on European legislation is the guaranteed grid access for electricity from renewable assets (European Commission, 2009b). For grid operators this implies that they must adjust and expand their grid according to the ongoing diffusion of renewable energy generation, potentially causing significant costs. Since grid operators function as natural monopolies, countries had to find ways in their national legislation to incentivize grid operators' minimization of expenditures for grid operation and expansion. In Germany, which hosts around 880 DSOs, an incentive regulation method was enacted in 2007, and applied since 2009, which simulates competition between grid operators through the comparison of key performance indicators, thus promoting efficiency (BNetzA, 2014; Deutscher Bundestag, 2007). Conversely, Portugal, with one dominant DSO, while also focused on measures to increase operational efficiency, also gives attention to find new ways to incentivize innovation activities (Eurelectric, 2016).

Smart grids can contribute to reduce the need for grid expansion and consequently reduce or postpone costs (Lavrijssen et al., 2016; Pudjianto et al., 2007; Siano, 2014). An essential element for reaping this benefit are smart meters since they allow for an active management of the devices behind the meter (cf. McHenry (2013) for further discussion). Considering 
this, the EU requested cost-benefit analyses of smart meter rollouts in their member states in 2009 and compared the insights gained in 2014. While 16 states decided to go for a comprehensive rollout until 2020, 7 states, including Germany and Portugal, remained skeptical (BMWi, 2013; European Commission, 2014a). While German policy-makers finally agreed to a moderate rollout until 2032 in the "Act on the Digitization of the Energy Transition" endorsed in 2016, no national legislation for a rollout exists in Portugal until today.

\subsection{Technological changes in grid operation}

In the past, DSOs solely received electricity from the upstream transmission system, which then was delivered to the local customers. With the diffusion of small-scale generation assets on the distribution grid level more electricity has now to be fed back to the higher voltage levels. This excess of local production can lead to limitations in the thermal capacity of the local grid infrastructure or violations of the permitted voltage band (Pepermans et al., 2005; Veldman et al., 2013). These limitations and violations can be mitigated in different ways, including a reinforcement of the local power lines, adjustable local power transformers, provision of reactive power, electricity storage devices as local buffers, re-dispatching of distributed generation assets and others, all having their specific individual pros and cons (Lopes et al., 2007). Figure 1 shows the recent evolution of the share of wind and solar in the total electricity generation, of which up to $90 \%$ is estimated to be connected to DSO networks, directly impacting grid operations (European Commission, 2017a). A similar topic is the one of grid stability and ancillary services where DSOs at present rely on conventional, centralized power plants. With those fading, renewable assets have to become better integrated, as the DSOs have to manage their grids in a much more active and "smarter" 
manner than in the past (Anaya and Pollitt, 2015; Ipakchi and Albuyeh, 2009; Lopes et al., 2007; Martinot, 2016; Reddy et al., 2014).

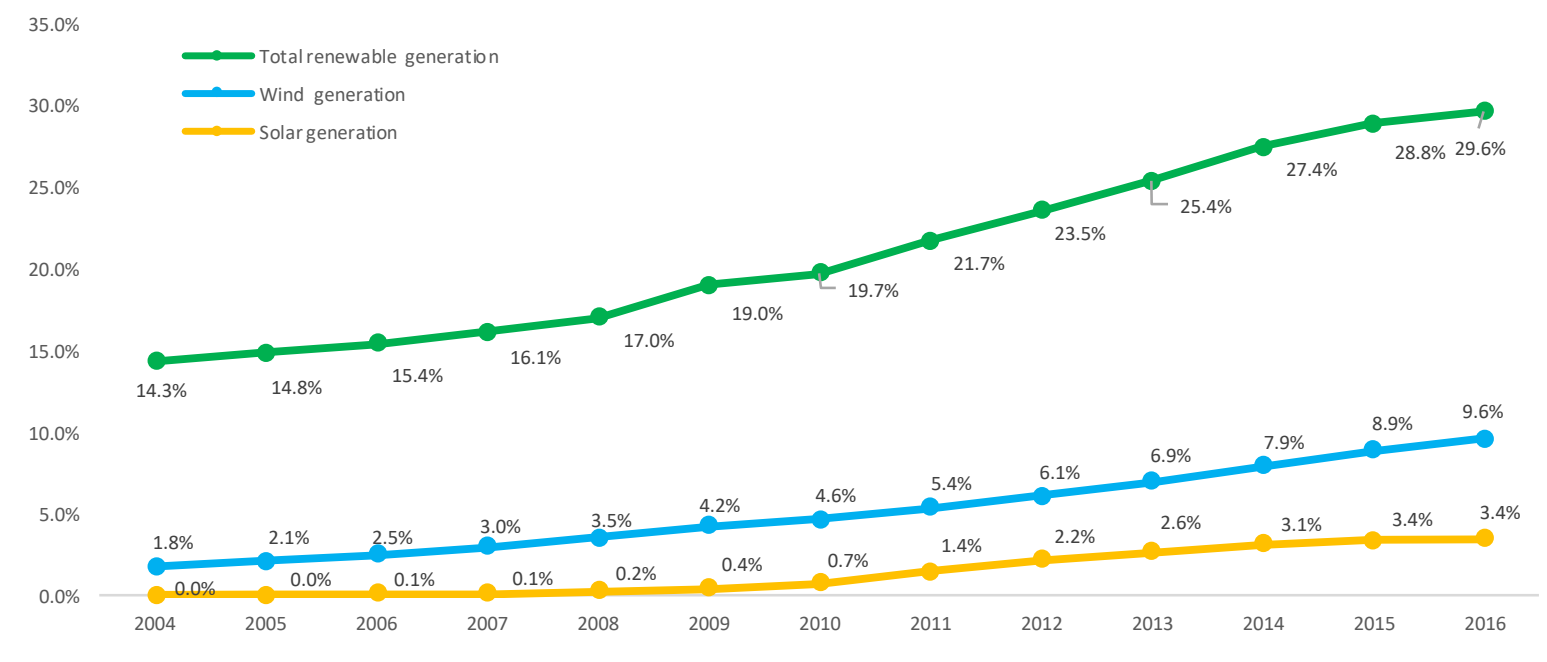

Figure 1. Share of renewables on total electricity generation for the EU-28. Source: Authors' elaboration from Eurostat (2018)

One popular form often mentioned is the grid-friendly operation of local flexible assets such as electric vehicles in the form of demand side management, as investigated by Dallinger et al. (2013) for California and Germany. Table 1 shows the evolution of electric vehicles and charging infrastructure in the EU-28.

Table 1. Electric vehicles and charging stations evolution for the EU-28. Source: Authors' elaboration from EAFO (2018), and EEA, 2016)

\begin{tabular}{lcccccccc}
\hline & $\mathbf{2 0 1 0}$ & $\mathbf{2 0 1 1}$ & $\mathbf{2 0 1 2}$ & $\mathbf{2 0 1 3}$ & $\mathbf{2 0 1 4}$ & $\mathbf{2 0 1 5}$ & $\mathbf{2 0 1 6}$ & $\mathbf{2 0 1 7}$ \\
\hline Electric vehicles on the road & & & & & & & & \\
\hline Battery electric vehicles & 700 & 9787 & 23919 & 47702 & 85413 & 143811 & 207239 & 328351 \\
\hline Plug-in hybrid electric vehicles & n.a. & 336 & 9350 & 35228 & 68627 & 158550 & 252735 & 349084 \\
\hline Total electric vehicles on the road & $\mathbf{7 0 0}$ & $\mathbf{1 0} \mathbf{1 2 3}$ & $\mathbf{3 3 2 6 9}$ & $\mathbf{8 2 ~ 9 3 0}$ & $\mathbf{1 5 4 0 4 0}$ & $\mathbf{3 0 2} \mathbf{3 6 1}$ & $\mathbf{4 5 9} 974$ & $\mathbf{6 7 7} \mathbf{4 3 5}$ \\
\hline & & & & & & & & \\
\hline Available charging stations & & & & & & & \\
\hline Normal charging & n.a. & 3882 & 13054 & 22528 & 32099 & 52960 & 82958 & 101947 \\
\hline High speed charging & n.a. & 13 & 296 & 1013 & 2349 & 6262 & 9775 & 14824 \\
\hline Total charging stations available & n.a. & $\mathbf{3 8 9 5}$ & $\mathbf{1 3 3 5 0}$ & $\mathbf{2 3 5 4 1}$ & $\mathbf{3 4 4 4 8}$ & $\mathbf{5 9 2 2 2}$ & $\mathbf{9 2 7 3 3}$ & $\mathbf{1 1 6 7 7 1}$ \\
\hline
\end{tabular}

n.a.: no information available 
This might turn out important since increasing production and consumption peaks could potentially impose massive costs for grid expansions unless a way is found to operate these assets in a grid-friendly manner (Palensky and Dietrich, 2011; Wood and Funk, 2017). However, this path to smart grids requires smart meters as a key element, as mentioned above. The rollout of these smart meters goes along with new challenges for DSOs, who often find themselves in the role of meter operators, in terms of safe digital communication, data property and privacy issues, and new technological specifications, e.g., in terms of installation and calibration (Depuru et al., 2011; Yan et al., 2013).

\section{Research design}

\subsection{Case study methodology}

The analysis of the adaptation dynamics of electricity distribution towards smart grids in the EU is conducted following a case study methodology, which supports the development of empirical insights through interaction with electricity distribution stakeholders by collecting data related to their real-world contextual setting (Dul and Hak, 2008; Krivokapic-Skoko and O'neill, 2011). This approach facilitates insight collection from stakeholders and contributes to the identification of existing and emerging challenges and opportunities. Moreover, it provides a flexible method through which multiple perspectives can be obtained (Yin, 2011). Considering the conceptual framework of LTS in which this research is developed, a case study research design supports an empirical approach aimed at gaining a better understanding of the sociotechnical transition of the electricity distribution industry. On the scope of transition studies' analytical approaches, the case study methodology falls within the initiative-based learning methodologies (Turnheim et al., 2015). Initiative-based approaches are driven by the importance to understand actor's perspectives and perceptions as shifts and adaptation occur, often considering their technological, organizational, and cultural aspects 
included in this study. Notwithstanding the context-rich insights attainable through this approach, it faces also the possible challenges of a bounded perception of the stakeholders engaged, limited by their immediate situation and constraints. However, this limitation is counterbalanced by the value of a detailed understanding of how transitions impact actors (Schot and Geels, 2008), which can contribute to adjustments to policies and incentives, or the identification of new priorities for DSO adaptation.

\subsection{Implementation and cases characterization}

The research design was implemented through nine multi-stakeholder workshops conducted between May 2016 and October 2017. Multi-stakeholder workshops represent an actionbased participatory element in this research (Kindon et al., 2007), due to their ability to generate discussion and facilitate insight collection across heterogeneous participants (Mahroum et al., 2016; Schut et al., 2015). A survey with open questions was designed to facilitate discussion during the workshops. Table 5 presents the covered dimensions, topics, and open questions of the analysis (Sreejesh et al., 2014). The questions selected for use during the workshops reflect the focus of the analysis to encompass business model, legislative, and technology aspects related to the adaptation of the electricity distribution industry. Figure 4 details the research design process.

The data collected through the workshops was coded by the research team, resulting in several topics within the broader categories considered in the survey with open questions: (1) business model and organizational issues; (2) operations, technology, and asset management; and (3) market design and regulation. Participating stakeholders represent two groups: stakeholders active in the electricity supply chain and stakeholders outside the electricity supply chain. The participants in the workshops are located in Germany (DE) and Portugal 
(PT) as two representative cases of the diverse dynamics of the electricity distribution in the EU (Eurelectric, 2016, 2013). Figure 1Figure 2 and Figure 3 contrast trends in the EU 28 with the cases of Germany and Portugal as indicative evidence of the representativeness of these case studies in the general EU context by looking at the evolution of renewables shares and electric vehicle market, as proxies for the distributed energy resources diffusion.

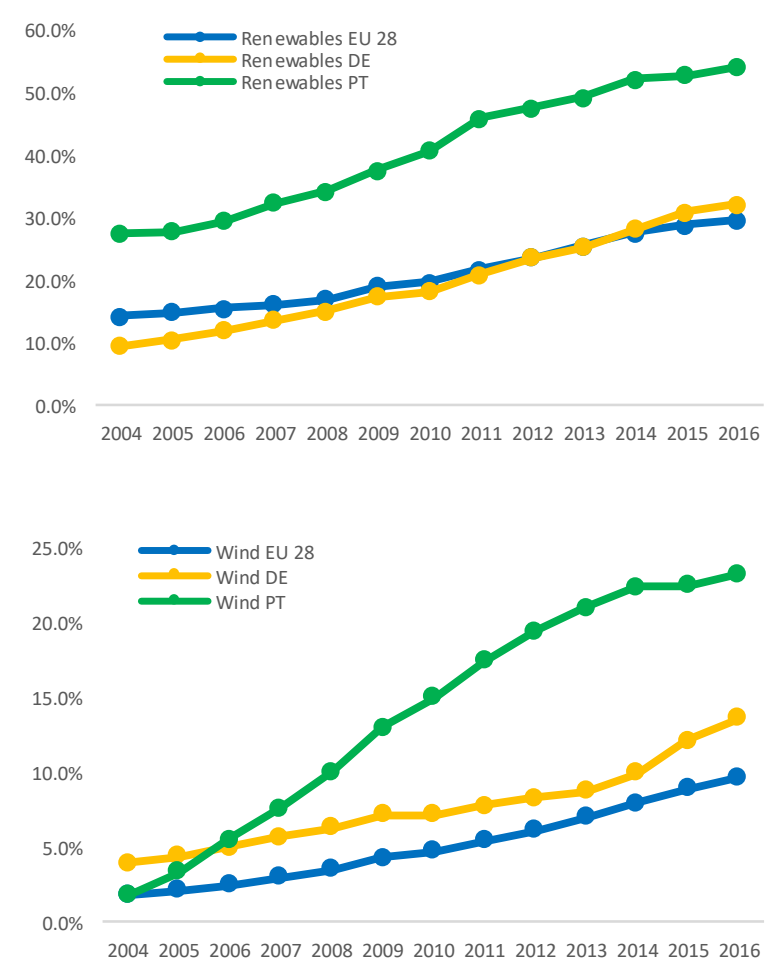




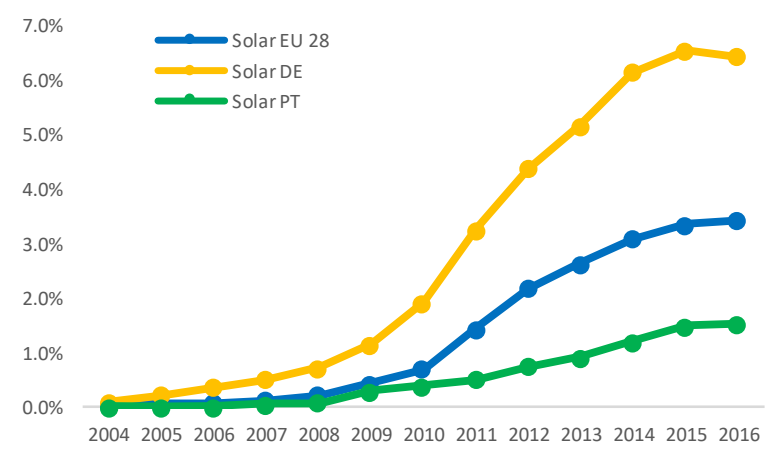

Figure 2. Share of total renewables, wind, and solar on total electricity generation for PT, DE, and EU-28. Source: Authors' elaboration from Eurostat (2018)

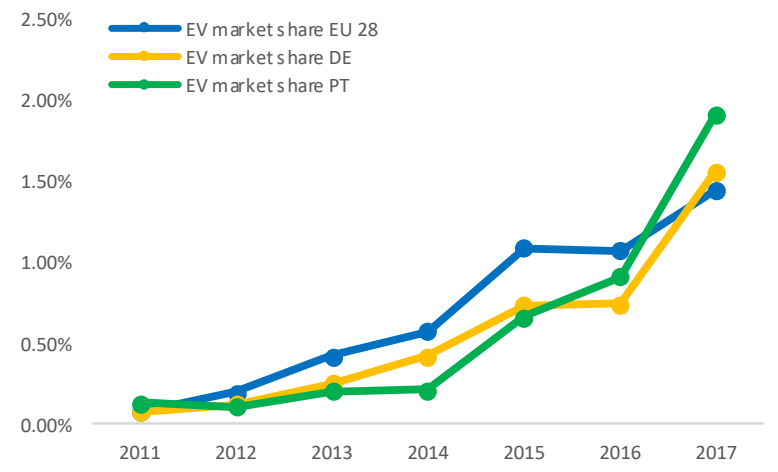

Figure 3. Electric vehicles' market share for PT, DE, and EU-28. Source: Authors' elaboration from EAFO (2018).

Table 2 provides additional details on the German and Portuguese electricity distribution industry characteristics through a set of indicators of industry structure, evolution, and infrastructure characteristics. 
Table 2. Electricity distribution characterization for Germany and Portugal. Authors' elaboration from Cambini et al. (2016);

Eurelectric (2013); Gangale et al. (2017); and My Smart Energy (2018a, 2018b).

\begin{tabular}{|c|c|c|c|c|}
\hline Electricity & distribution characterization & Germany & Portugal & EU 28 \\
\hline \multicolumn{5}{|c|}{ Distribution industry structure } \\
\hline & Distribution sector concentration & Low & Medium & \\
\hline & Regulatory mechanism & Incentive & Hybrid & \\
\hline & Innovation support mechanism & None & Enhanced rate of return & \\
\hline & DSO Ownership & Largely public & Largely private & \\
\hline & DSOs with > 100000 consumers & 75 & 3 & $190^{\mathrm{a}}$ \\
\hline & Connected consumers & 49294962 & 6137611 & $263370337^{\mathrm{a}}$ \\
\hline & Distributed power (TWh/Year) & 511 & 52 & $2581^{\mathrm{a}}$ \\
\hline \multicolumn{5}{|l|}{ Industry evolution } \\
\hline \multirow{3}{*}{ No. of DSO } & $\mathrm{s}$ in 1997 & 1000 & 4 & $2553^{\mathrm{a}}$ \\
\hline & No. of DSOs in 2003 & 900 & 1 & $1762^{\mathrm{a}}$ \\
\hline & No. of DSOs in 2010 & 880 & 13 & $2335^{\mathrm{a}}$ \\
\hline \multicolumn{5}{|c|}{ Infrastructure characteristics } \\
\hline \multirow{3}{*}{$\begin{array}{r}\text { Distribution line } \\
\text { voltage }(\% \text { of } \\
\text { total distribution } \\
\text { infrastructure) }\end{array}$} & $<1 \mathrm{KV}$ & $65 \%$ & $62 \%$ & $60 \%^{b}$ \\
\hline & $1-100 \mathrm{KV}$ & $30 \%$ & $38 \%$ & $37 \%^{b}$ \\
\hline & $>100 \mathrm{KV}$ & $5 \%$ & - & $3 \%^{b}$ \\
\hline \multirow{3}{*}{$\begin{array}{r}\text { Grid length and } \\
\text { components }\end{array}$} & Line density $\left(\mathbf{k m}\right.$ lines/(km $\left.{ }^{2}\right)$ & 5 & 2.4 & $2.7^{\mathrm{b}}$ \\
\hline & Overall line length $(\mathbf{k m})$ & 1772696 & 222627 & $9952844^{a}$ \\
\hline & No. of MV and $L V$ transformers & 461900 & 64458 & $3918178^{a}$ \\
\hline \multirow{3}{*}{$\begin{array}{r}\text { Smart grid } \\
\text { development }\end{array}$} & $\begin{array}{r}\text { Smart grid investments }(€ / M € \text { GDP } \\
2015)\end{array}$ & 267.08 & 495.81 & $379.32^{b}$ \\
\hline & Smart grid investments (€/Capita) & 9.86 & 8.61 & $13.01^{\mathrm{b}}$ \\
\hline & Smart meter roll-out & $\begin{array}{c}\text { The German government } \\
\text { expects a rollout of } 30 \% \text { of } \\
\text { smart meters ( } 15.8 \mathrm{M} \text { meters) } \\
\text { by } 3032\end{array}$ & $\begin{array}{l}\text { No nationwide rollout } \\
\text { mandated. Several pilot } \\
\text { projects are under way. }\end{array}$ & \\
\hline
\end{tabular}

${ }^{\mathrm{a}} \mathrm{EU}-28$ total; ${ }^{\mathrm{b}} \mathrm{EU}-28$ average. 
Our findings are anonymized. However, background information on the participating stakeholders is provided. In terms of stakeholders active along the electricity supply chain, 4 distribution system operators participated in the workshops, operating under different structural and regulatory frameworks. The participating delegates from DSOs represent a heterogeneous group, which we deem relevant as a source of complementary perspectives on adaptation issues towards smarter grids. Table 3 provides information regarding their scale in terms of connected consumers, the degree of separation of electricity distribution activities from other activities through unbundling, as well as the regulatory framework and market structure and operational characteristics 123 . The stakeholders outside the electricity supply chain include the research group conducting the study, a research center focused on smart grids, and the innovation unit of an electric utility group holding (see Table 3).

1 Regarding the regulatory framework characteristics our participants are subject to either incentive-based or hybrid approaches. An incentive-based approach offers possibilities for DSOs to increase their financial earnings if certain efficiency improvement targets are met (Cambini et al., 2016). A hybrid approach is based on a combination of cost-and incentive-based a pproaches. Cost-based regulation enables DSOs to recover their investments plus a set rate of return. Hybrid approaches often result in combinations of a cost-based approach on capital expenditures and an incentive-based approach for operational expenditures (Cambini et al., 2016; Eurelectric, 2014).

2 Considering innovation incentives these can include access to a higher rate of return for innovation-related investments, as well as a specific mechanisms to adjust revenues throughout the regulatory period for research and development-related costs (Eurelectric, 2016).

${ }^{3}$ Market concentration is a measure of the electricity distributed by the DSOs in a Member State (Eurelectric, 2013). Low concentration exits when the electricity distribution market is based mostly on small, local DSOs, for which the three largest DSOs distributed less than $50 \%$ of the totaldistributed electricity. Medium centration occurs when one DSO is responsible for more than $80 \%$ of the total distributed electricity, or when the three largest DSOs distribute more than $60 \%$ of the electricity. 
Table 3. Stakeholder description.

Stakeholders within the electricity sector supply chain.

\begin{tabular}{|c|c|c|c|c|c|c|c|c|}
\hline \multirow[b]{2}{*}{ Stakeholder } & \multirow[b]{2}{*}{ Unbundled } & \multirow[b]{2}{*}{$\begin{array}{l}\text { Consumers } \\
\text { (approx.) }\end{array}$} & \multicolumn{2}{|c|}{ Operations } & \multicolumn{2}{|c|}{ Regulatory framework } & \multicolumn{2}{|c|}{ Market structure } \\
\hline & & & $\begin{array}{c}\text { Distributed } \\
\text { electricity } \\
\text { (GWh/year) }\end{array}$ & $\begin{array}{l}\text { Total grid } \\
\text { length } \\
(\mathrm{KM})\end{array}$ & $\begin{array}{l}\text { Regulatory } \\
\text { approach }\end{array}$ & $\begin{array}{l}\text { Innovation } \\
\text { incentives }\end{array}$ & $\begin{array}{c}\text { DSO } \\
\text { Concentration }\end{array}$ & Ownership \\
\hline DSO A & Yes & 4000000 & 16428 & 182461 & Incentive & No & Low & $\begin{array}{l}\text { Largely public, } \\
\text { municipal } \\
\text { ownership }\end{array}$ \\
\hline DSO B & Yes & 100000 & 2681 & 3366 & Incentive & No & Low & $\begin{array}{l}\text { Largely public, } \\
\text { municipal } \\
\text { ownership }\end{array}$ \\
\hline DSO C & Yes & 5000000 & 44599 & 225422 & Hybrid & Yes & Medium & Largely private \\
\hline DSOD & No & 15000 & 5.9 & 321.3 & Incentive & No & Low & $\begin{array}{l}\text { Largely public, } \\
\text { municipal } \\
\text { ownership }\end{array}$ \\
\hline \multicolumn{9}{|c|}{ Stakeholders outside the electricity sector supply chain. } \\
\hline \multicolumn{2}{|c|}{ Stakeholder } & \multicolumn{7}{|c|}{ Description } \\
\hline \multicolumn{2}{|c|}{ Researchers and Academics A } & \multicolumn{7}{|c|}{$\begin{array}{l}\text { This is the research group conducting the study. These comprise researchers from the University of Coimbra, } \\
\text { Coimbra, Portugal and from RWTH Aachen University, Aachen, Germany. }\end{array}$} \\
\hline \multicolumn{2}{|c|}{$\begin{array}{l}\text { Electricity Utility Innovation } \\
\text { Unit A }\end{array}$} & \multicolumn{7}{|c|}{$\begin{array}{l}\text { The electric utility company represented by this stakeholder owns distribution systems in Southern America and } \\
\text { Southern Europe, as well as other supply chain activities. The innovation unit is responsible for driving disruptive } \\
\text { change for the group of companies owned. }\end{array}$} \\
\hline \multicolumn{2}{|c|}{ Research Center A } & \multicolumn{7}{|c|}{$\begin{array}{l}\text { This research center focuses on power systems and power economics research, with a specific focus on smart grids } \\
\text { and new electricity sector market design. }\end{array}$} \\
\hline
\end{tabular}

Table 4 provides details on the workshops, including the number of participants, stakeholder groups represented, workshop goals, the region where these were delivered, as well as dates (month and year) they were conducted. 
Table 4. Research workshop details.

\begin{tabular}{ccll}
$\begin{array}{c}\text { Workshop } \\
\text { no. }\end{array}$ & $\begin{array}{c}\text { No. of } \\
\text { participants }\end{array}$ & \multicolumn{1}{c}{ Stakeholders groups } & \multicolumn{1}{c}{$\begin{array}{c}\text { Workshop goals } \\
\text { date }\end{array}$} \\
\hline 1 & 4 & Researchers and Academics A (n=4) & Establish research framework \\
\hline 2 & 6 & Researchers and Academics A (n=5), DSO A (n=1) & $\begin{array}{l}\text { Semi-structured interviews, and } \\
\text { data collection }\end{array}$ \\
\hline 3 & 6 & Researchers and Academics A (n=4), DSO B (n=2) & $\begin{array}{l}\text { Semi-structured interviews, and } \\
\text { data collection }\end{array}$ \\
\hline 4 & 5 & Researchers and Academics A (n=5) & $\begin{array}{l}\text { Data analysis, and refine research } \\
\text { framework }\end{array}$ \\
\hline 5 & 7 & Researchers and Academics A (n=5), DSO C (n=2) & $\begin{array}{l}\text { Semi-structured interviews, and } \\
\text { data collection }\end{array}$ \\
\hline 6 & 6 & $\begin{array}{l}\text { Researchers and Academics A (n=5), } \\
\text { Electricity Utility Innovation Unit A (n=1) }\end{array}$ & $\begin{array}{l}\text { Semi-structured interviews, and } \\
\text { data collection }\end{array}$ \\
\hline 7 & 7 & Researchers and Academics A (n=5), DSO D (n=2) & $\begin{array}{l}\text { Semi-structured interviews, and } \\
\text { data collection }\end{array}$ \\
\hline 9 & 5 & $\begin{array}{l}\text { Researchers and Academics A (n=4), } \\
\text { Research Centre A (n=1) }\end{array}$ & $\begin{array}{l}\text { Semi-structured interviews, and } \\
\text { data collection }\end{array}$ \\
\hline 4 & Researchers and Academics A (n=4) & $\begin{array}{l}\text { Data analysis, and discussion of } \\
\text { results }\end{array}$ \\
\hline
\end{tabular}

Table 5. Open questions for workshops.

\begin{tabular}{|c|c|c|}
\hline $\begin{array}{c}\text { Analysis } \\
\text { dimension }\end{array}$ & $\begin{array}{c}\text { Questionnaire } \\
\text { topic }\end{array}$ & Questions \\
\hline \multirow[t]{2}{*}{$\begin{array}{l}\text { Business } \\
\text { model and } \\
\text { organizational } \\
\text { issues }\end{array}$} & $\begin{array}{l}\text { Strategy and } \\
\text { operations }\end{array}$ & $\begin{array}{l}\text { - What is your perspective in terms of the activities presented recently as grey areas to be performed by } \\
\text { DSOs? i.e.: electric mobility infrastructure, smart metering equipment installation and maintenance, energy } \\
\text { efficiency services, data management, and integration of distributed energy resources. } \\
\text { - What are the main drivers for operational efficiency improvements? } \\
\text { - What is the value of flexibility for DSOs? } \\
\text { - Do you outsource any business activities? Which ones? } \\
\text { - How engaged are you in the energy transition and DSO role adaptation? } \\
\text { - Is the operation of small isolated areas a challenge for DSOs? }\end{array}$ \\
\hline & $\begin{array}{l}\text { Organizational } \\
\text { change }\end{array}$ & $\begin{array}{l}\text { - What are the main drivers for engaging in research and development projects? } \\
\text { - Have any new business units or departments been created because of the changes in the power sector? }\end{array}$ \\
\hline $\begin{array}{l}\text { Technological } \\
\text { adaptation }\end{array}$ & $\begin{array}{l}\text { Technology } \\
\text { and innovation }\end{array}$ & $\begin{array}{l}\text { - What are your means to increase the service availability and quality of service levels? } \\
\text { - How does the DSO handle the connection of new distributed energy resources to the distribution gird? } \\
\text { - What forecasting techniques are applied for renewable energy plants connected to the distribution grid? }\end{array}$ \\
\hline \multirow{2}{*}{$\begin{array}{l}\text { Market } \\
\text { design and } \\
\text { regulation }\end{array}$} & $\begin{array}{l}\text { Regulatory } \\
\text { framework } \\
\text { and policy } \\
\text { aspects }\end{array}$ & $\begin{array}{l}\text { - What is the impact of the regulatory framework in the business operations? } \\
\text { - Does the } 100000 \text { customers rule for unbundling result in an advantage or a disadvantage for DSOs? }\end{array}$ \\
\hline & Market design & $\begin{array}{l}\text { - What is your perspective on the appearance of new market players in the electricity sector in the future? } \\
\text { - What is your perspective on electricity distribution market structure? }\end{array}$ \\
\hline
\end{tabular}




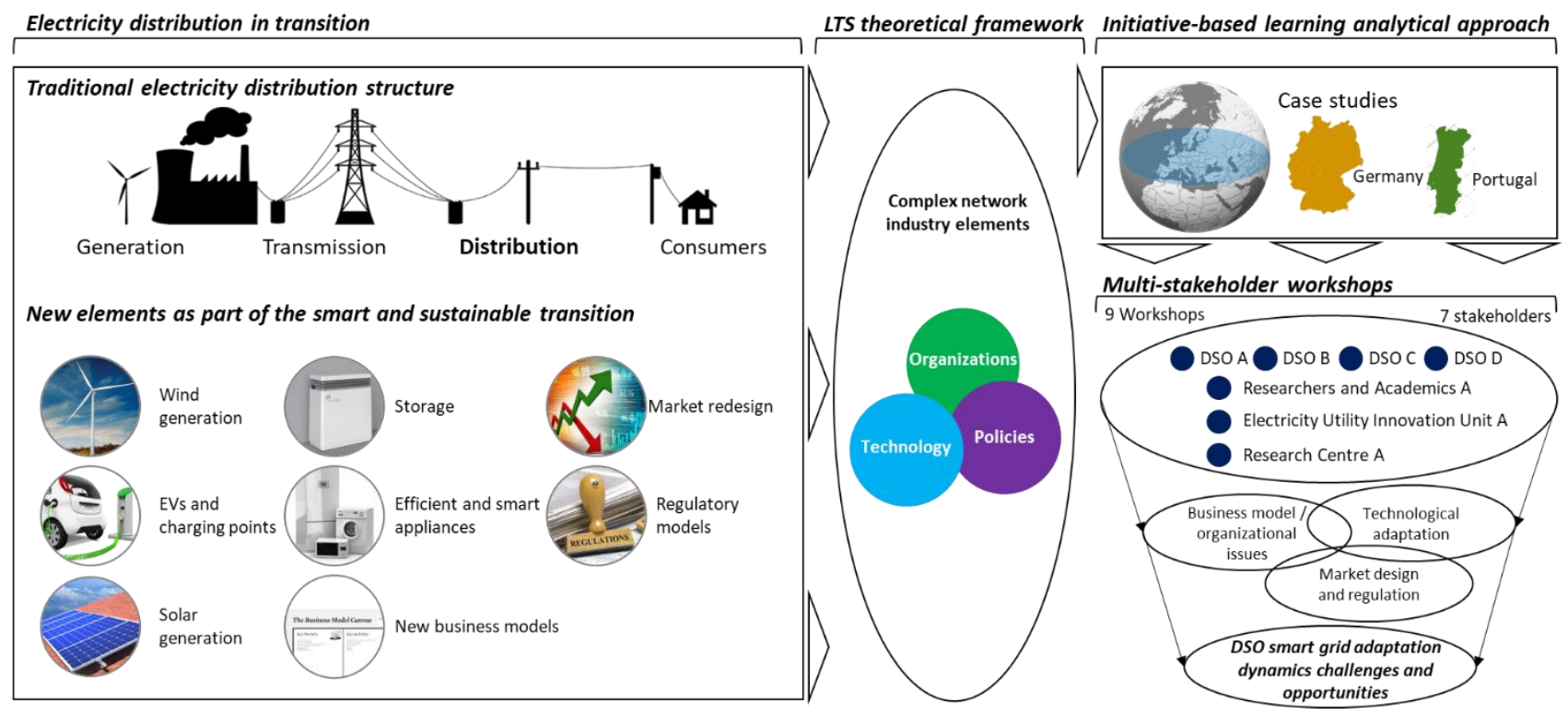

Figure 4. Research design. Authors' own elaboration.

\section{Insights from the multi-stakeholder workshops}

\subsection{Operations, technology, and asset management}

\subsubsection{Integration of distributed energy resources/distributed generation}

The increase of distributed generation units connected to distribution grids is contributing to a more decentralized electricity system. Their integration on traditional distribution operations is a challenge for DSOs, with wind generation being the most challenging technology. "The biggest challenge in terms of integration of renewables are wind farms, however we must also consider smaller scale technologies such as $P V$ and the impacts these might have." (representative DSO B). The extent of these challenges is stronger in rural areas, where more opportunities to deploy distributed generation exist, particularly wind, given land 
availability, as opposed to urban areas ${ }^{4}$ where deployed capacity is generally lower, and mostly solar PV. "The integration of renewable energy generation at the distribution level is particularly challenging, considering that in some areas production is between 15 to 50 times higher than consumption. This is often the case in rural areas, which require expensive grid expansion to handle the increased distributed generation." (representative DSO A). Regarding distribution infrastructure, increases in distributed generation will impact mostly the low- and medium-voltage segments of the grid. As described in section 2.3, the growing share of distributed generation connected to the networks challenges also the traditional configuration and use of up-stream electricity infrastructure. This was confirmed by our experts who also observed an impact on network stability and a rapid increase in investments needs. "We have to improve transformers capacity in several districts very quickly even though such measures are time and capital intensive. Several solutions exist, but the costs will be very high." (representative DSO B).

\subsubsection{Operations and maintenance}

Changes on how electricity is distributed to consumers requires adaptation in terms of operation and maintenance of the grids. An exploitation of flexibility potentials within the distribution grid is one possible way to meet the upcoming challenges of a distributed energy system and could potentially reduce the need for investments related to grid expansion. "We have some flexibility management possibilities, but these are very limited. Flexibility management can be a solution instead of grid expansion." (representative DSO B).

4 "This is not a significant challenge for us. We have no wind generation connected to the grid, and only a small share of $P V$. This is related to the fact that our distribution operations concentrate in an urban area." (representative DSO D) 
Furthermore, distributed generation can contribute to significant changes in infrastructure usage in isolated areas, where consumption remains unaltered while electricity generation increases. Larger DSOs do not consider the operations and maintenance in these areas as challenging. "Operating and maintaining small isolated areas is not a challenge, it is in fact okay, and is a good business." (representative DSO A). Conversely, small DSOs have a different perception, considering this as a challenge. "Small isolated areas sometimes can be challenging from an operational perspective." (representative DSO B). These different insights call for more attention regarding the impact of DSO size in distribution network operation and maintenance.

Redesigning the operations of distribution networks will benefit from a clearer understanding of the role of the DSO in the future. Managing system flexibility and enabling flexibilities from distributed generation, electricity storage, and demand response can contribute to value creation (Damsgaard et al., 2015). However, a consistent legislative framework is needed to settle the options and duties of (monopolistic) DSOs.

\subsubsection{Smart grid technologies}

Smart grid technologies were discussed as enabling components to facilitate the adaptation of distribution operations. Smart grid technologies can include monitoring and automation components that increase access to grid data and control capabilities. Moreover, these can include components that enable the integration and interaction with distributed generation and distributed energy resources. For instance, electric vehicles and the associated charging

infrastructure were indicated as having the potential to bring disruption to the electricity distribution sector. However, DSOs are not certain regarding the most adequate implementation plan. "In the current context electric mobility can be a game changer. 
However, we need to understand if there will be charging stations at home? if charging stations are stranded capital? And if there should be a subsidy for charging stations?" (representative DSO A). Moreover, electricity storage represents also an interesting future option, for which a supportive regulatory framework should be established. "In addition, storage is also seen as an opportunity for disruption. Regulation should be revised to set the right incentives." (representative DSO A).

Smart grid technologies are expected to enable new services and contribute to increased consumer management capabilities. "Our smart grid projects focus on either smart metering or distribution automation applications. The type of remote services possible for the DSO as a smart meter operator are for instance to connect a consumer, disconnect a consumer due to a non-payment, automated billing, etc." (representative DSO C). The added value resulting from evolving towards smart grids relates to the possibilities to access new data. "Much of the value that can be created comes from data currently collected, and data that can be collected in the future through more sensors, smart meter deployment, and partnerships with external data providers." (representative Electricity Utility Innovation Unit A).

Standardization is essential for a successful adaptation of DSOs given the increasing deployment of smart meters, grid automation technologies, control devices, and other smart grid technologies (representative Research Centre A, representative DSO C). Moreover, the ability of DSOs to adopt smart grid technologies is influenced by their scale. Smaller DSOs notice grater challenges for rolling out innovative technologies "The rollout of smart grid technology, in this case smart meters, is challenging for small DSOs." (representative DSO D). 


\subsubsection{Smart meter technologies}

Smart meters provide remote measurement and communication of electricity usage in smart grids, and are often referred to as the initial step to take in a smart grid deployment plan (Kabalci, 2016; Sharma and Saini, 2015). The added value of smart meters lies on their ability to provide more detailed information about grid usage, as well as increase fault location capabilities. "From a grid expansion perspective, having more data, through more monitoring points can help in understanding the network better." (representative DSO D). Moreover, smart meters support observability, and can contribute to improvements in network congestion management (representative Research Centre A). However, the potential for smart meters is lowered without dynamic pricing of electricity. "Smart meters can provide better information about the grid. However, these have little potential in a one-tariff system. Tariffs should be dynamic for smart metering to be attractive" (representative DSO A). Nonetheless, while smart metering technologies are perceived as important and of addedvalue, our stakeholders did not consider it necessary to have a smart meter at every end-point, and mentioned that having data from smart meters collected from $10 \%$ to $15 \%$ of the endpoints only would be sufficient ${ }^{5}$.

These insights provide a valuable perspective on the DSOs perception on their benefits related to large-scale rollouts of smart meters. To estimate the value of roll-out on a macroeconomic scale, these benefits have to be contrasted with the associated costs.

\footnotetext{
5 "We don't see the need for a smart meter in every end-point. If $10 \%$ of the homes have a smart meter in a specific area it is enough to provide the necessary information on the status of the grid." (representative DSO A, representatives of DSO B, DSO C, and DSO D presented agreeing views).

"Smart meters could help DSOs to support the observability of the grid and contribute to better congestion management." (Research Center A)
} 
Therefore, the EU requested the member states to conduct a cost-benefit analysis in its Third Energy Package set a target of $80 \%$ of smart meters by 2020 whenever this cost-benefit analysis is positive (European Commission, 2009a, 2014b). As described in section 2.3, this cost-benefit analysis in Germany turned out negative with smart meters being feasible only above a certain consumption threshold (BMWi, 2013). For Portugal a first study indicated positive results, however, due to sever economic challenges, Portugal decided to review the original findings and considered the analysis inconclusive also refraining from the ambitious 80\% target of the EU (ICCS-NTUA and AF Mercados EMI, 2015). The observed position across DSOs can offer new possibilities for other players to support the deployment of smart meters in the EU. Despite this insight on the perceived value of smart meters the responsible party for implementation and ownership across the EU are mainly DSOs (European Commission, 2014a, 2017b).

Connected to the perception of limited added value from a full rollout of smart meters, alternative technology options are being considered to support DSO adaptation. The need for information on every end-point of the grid is perceived as limited. "We are not sure if a smart meter is the right device to provide us with the information we need from the network. The interest in more information regarding the current grid conditions is rather small. We see no need for smart metering for real-time consumption measurement. Metering of only certain parts of the grids is sufficient to reveal enough information about distributed generation." (representative DSO B).

Also, the rollout of smart meters encompasses technical and economic challenges. Technical challenges are related with the complexity around data management and cybersecurity. Economic issues are related with the potentially shorter lifespan of smart meters, in 
comparison to its electromechanical predecessors. "The deployment of smart metering can increase complexity around data collection and cybersecurity issues. Moreover, the possible provision of new services and functionalities adds to the concerns associated with hacking. This adds to the challenges associated with costs, and cost allocation for consumers, Traditional meters have had a lifetime of 16 years. Smart meters have an expected lifetime of 8 years, with possibilities to last up to 13 years." (representative DSO D). Standardization is also an important aspect when it comes to smart meter technologies' adaptation and adoption by DSOs. "Right now, DSOs are analyzing communication protocols and how these can be standardized." (representative DSO D).

\subsubsection{Legacy technologies}

Adapting electricity distribution networks has been generally discussed around the importance of innovative technologies and approaches to network operations. However, legacy technologies are also a relevant element in supporting DSOs adaptation. These represent existing technologies, which have been incrementally improving and are perceived as low-cost and low-risk options. "In addition to the disruptive technology options there are also low-cost legacy technologies that when implemented result in significant efficiency increases for the DSOs. These include controllable low voltage transformers, and standardized automated controls." (representative DSO A). The following example on the relevance of legacy technologies was provided: "Our substations are quite old but the automation present in them from the 1980s works well enough." (representative DSO C).

Grid expansion is mostly within the scope of legacy technologies and has always been part of DSOs operations. Despite their historical experience, grid expansion is an increasingly challenging task due to location constraints for both transformer stations and lines. "We have 
clear plans for grid expansion and we plan to pursue them. These expansion plans are mostly related with building new lines. This brings challenges related to the fact that it is not easy to find places to build new transformer stations, as well as the fact that most of the lines must be planned as underground lines being costlier and less durable." (representative DSO B). Despite the challenges, grid expansion is a priority for DSOs. "At present we are concerned with the building and maintenance of the grid." (representative DSO B).

\subsection{Business model and organizational issues}

\subsubsection{Existing business model}

The significant changes in the technology and regulatory environment (cf. section 4.3) suggest that also the underlying business model of electricity distribution and value creation approach might have to be adapted or even completely redeveloped. "Our current business model is hardly profitable, and we expect legislative changes in the future. Still, we are not taking an active role in contributing to shape these future regulations." (representative DSO A). Despite the challenges resulting from existing business models, electricity distribution is an interesting business, which can benefit from timely adaptation to the changes in technologies and policies. This adaptation requires understanding the role of DSOs in providing or facilitating new services. "Being a network company only (unbundled) is a good place to be, there are good chances to do new tasks in the future. What is important is to start these new tasks." (representative DSO B).

\subsubsection{Business restructuring and mergers}

Adaptation of the electricity distribution industry is intertwined with an adaptation of the entire electricity sector supply chain. Changes in the electricity sector have resulted in restructuring and mergers across utilities, aimed at increasing economic performance and 
improving their position to engage in new business areas. "Due to financial turmoil our mother company is splitting into two companies to capture capital from the markets. One of the companies will keep all the generation and trading related activities. A new company will keep the distribution network, renewable energy, and retail-related activities, as the more profitable business areas." (representative DSO A).

An example of these restructuring efforts has been observed in two German utilities, E.ON and RWE. In 2016, E.ON's restructuring approach was based on a demerger that resulted in the creation of a spin-off company, Uniper, covering the unregulated business activities. RWE, following a different strategy, also demerged, but retained its unregulated activities, and created a spin-off company, innogy, for distribution grids, retail, and renewables (Zank et al., 2016). After this demerger actions, in 2018 E.ON presented a takeover offer over the newly created innogy, with the goal to create two more stable players, one focusing on networks and retail activities - the New E.ON, and one focusing on generation and trading the New RWE. This restructuring aims to contribute to simplify the two utilities corporate structures, making them more transparent and easier to valuate. Moreover, this merger can reduce the risk of acquisitions by foreign investors (E.ON, 2018; E.ON and RWE, 2018; Zank, 2018). Figure 5 describes the evolution through demergers and mergers and acquisitions for these two utilities. 


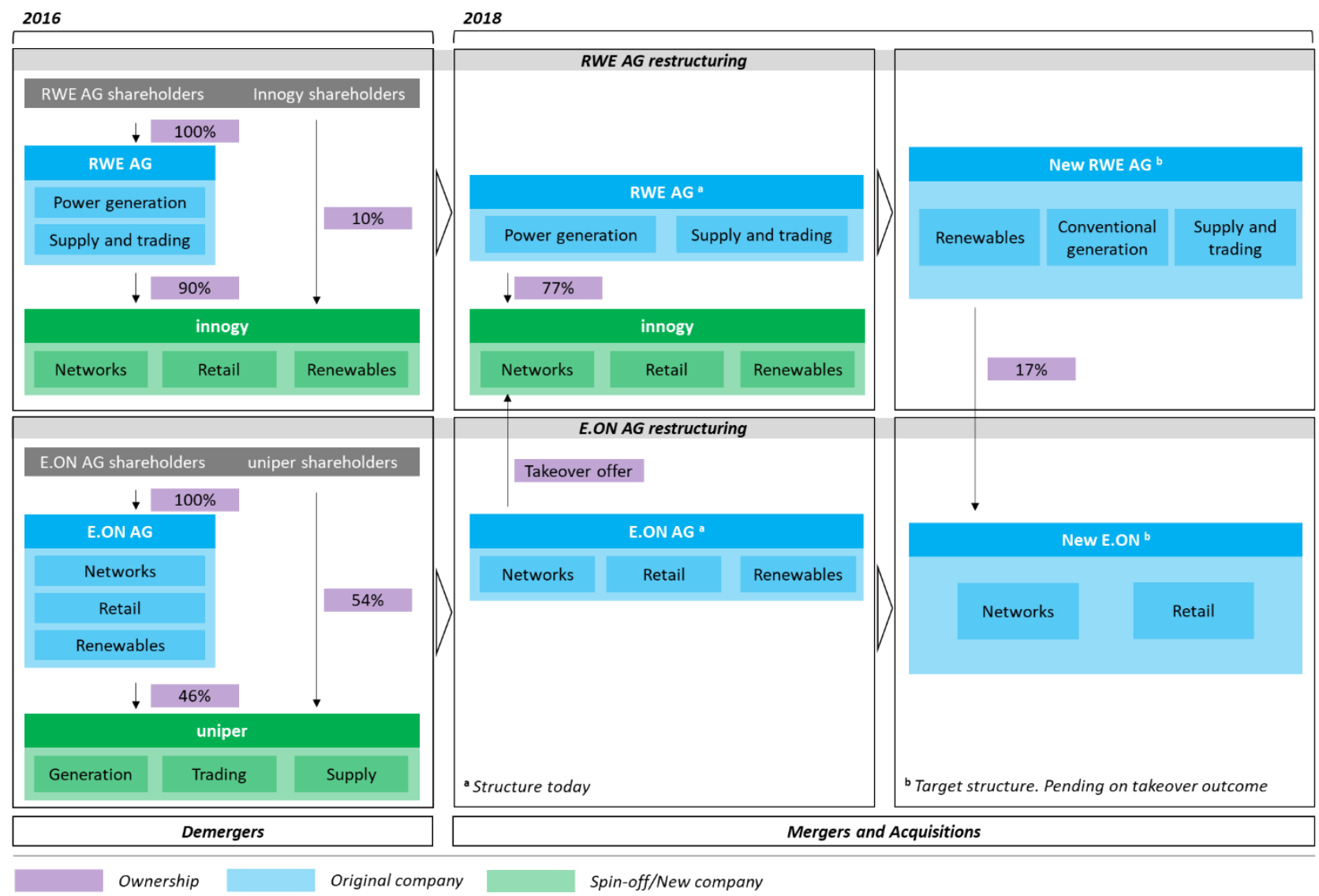

Figure 5. RWE and E.ON restructuring. Author's elaboration from E.ON (2018), E.ON and RWE (2018), Zank (2018), and Zank et al. (2016).

Mergers are considered an opportunity by small DSOs, which are looking for ways to reach greater economies of scale. "Right now, we are considering merging with another DSO. This merger is needed because we are constantly being pushed to reduce our operational costs to improve our efficiency factor. Because of this more than 50\% of our employees had to be fired in recent years. In line with this, we estimate the best conditions for medium/big DSO players in the future" (representative DSO B). Moreover, collaboration across smaller scale DSOs has been considered as an option to overcome challenges for technology acquisition. “We joined 7 other DSOs, servicing altogether a consumer population of some 200,000 to achieve greater economies of scale for acquiring technology." (representative DSO D). 
However, the experts from academia pointed out that there are also several cases where big DSOs lost concessions when the municipalities decided to found and own, local energy supplier/grid operator.

\subsubsection{Innovation}

Collaborative innovation efforts through Research and Development (R\&D) projects are being pursued by DSOs as a source of knowled ge and capability development for integrating and operating new technologies. DSOs are engaged in exploring new grid technologies and services. "We are participating in innovation projects and $R \& D$ in partnership with academic institutions. Our projects include advanced usage of smart meters, central battery storage and intelligent control of the systems." (representative DSO A). In terms of their approach to innovation, DSOs are interested in both exploitation and exploration. Exploration activities are concerned with understanding how new technologies and processes can be part of the electricity distribution industry. These include projects focusing on smart meter integration, storage integration, and intelligent control of systems. Also, through the development of virtual power plants, integration of solar photovoltaic (PV) systems. Exploitation activities focus on more traditional aspects of the electricity distribution operations. These include improvements in asset management, as well as innovations in business processes. "Complementing our more disruptive applications, we develop internal projects to support the innovation in asset management and business processes." (representative DSO C).

While being engaged in innovation-driving efforts is an important aspect, this activity is still challenged by a corporate culture with considerable levels of inertia to changes that embody unfamiliar technologies, processes, and stakeholders. "As the electricity sector has been to a 
large extent tied to stringent regulations and legacy technologies, certain innovation proposals are hard to pass through. Here having an internal innovation unit enables greater levels of confidence and buy-in from internal decision makers, that external players with disruptive ideas and proposals would not have." (representative Utility Innovation Unit A).

Concrete examples of the existing inertia to engage in disruptive transformation processes were discussed. For instance, the creation of an innovation hub to mobilize disruptive innovation efforts was considered as unacceptable on the scope of the DSO strategy. "Our unit proposed the creation of a digital energy disruptor hub outside of the company, which would foster disruptive ideas for the electricity sector. The executive board and internal decision makers annihilated the idea, claiming it would cannibalize our business." (representative Utility Innovation Unit A). Another example was associated with a proposal to submit the DSOs smart meters to an ethical hacking group, to better understand the extent of the DSOs cybersecurity vulnerabilities. "We as innovation unit proposed to our DSO that the smart meters being deployed would go through an ethical hacking consulting firm to understand the extent of cybersecurity threats. The board did not feel comfortable with the idea and rejected it." (representative Utility Innovation Unit A). This gives a sense that there are things that should rather remain unknown, and that maybe research must be conducted outside the companies themselves.

\subsubsection{Future business model}

The future business model for DSOs is expected to enable value creation and capture through flexibility management services. DSOs are willing to provide new services and integrate new technologies, therefore expanding the scope of their activities and responsibilities. "The future of our business requires operating flexibility to reduce the network operational costs 
and make the most of distributed energy resources and flexible demand. Moreover, we see a future in which we include new smart elements to operate our networks, such as new transformers, and where we are responsible for the coordination of the ancillary services for the system." (representative DSO A). Managing electricity storage units is considered as one of the opportunities within flexibility services. "We want to be able to contract storage to use it for grid balancing. We see a future in which one of our roles is to provide ancillary grid services." (representative DSO B).

In addition to the emphasis on system flexibility management, creating value from data is one of the opportunities considered promising in a more digital electricity system. These opportunities result from the direct access to new data that DSOs benefit when integrating smart meters and sensors as part of grid modernization actions. Moreover, access to data from third parties can contribute for creating data-driven services. However, delivering these benefits from data will only be possible through a shift in DSOs conservative culture regarding data access and sharing. "However, while data represents significant opportunities for new service development, it is still difficult to get buy in from decision-makers on matters that involve sharing data or using it in new ways. Previous attempts to implement ideas that require data sharing from the DSO to other partners resulted in reactions such as: 'That is not what we do', 'We are a regulated business, we are not supposed to share data', and 'That is not part of our operations'. (representative Electricity Utility Innovation Unit A). The possible business model changes around data do not necessarily indicate that DSOs will become actively engaged in delivering new services for electricity consumers. This may be a more suitable role for other market players. Nonetheless, DSOs can play an important role in facilitating those market players that have the capabilities to deliver innovative services. 
Future business models around data and digitalization can benefit from blockchain technology (Aitzhan and Svetinovic, 2016; Knirsch et al., 2018; Mengelkamp et al., 2017b), similar to the approach being followed by LO3Energy in Brooklyn, New York (Mengelkamp et al., 2017a). While blockchain and the possibilities for introducing smart contracts seem attractive, it is possible to do similar things without any blockchain technology. However, at least both big DSOs (A and C) indicated that they would like to be perceived as pro-actively considering innovative and potentially disruptive technologies such as blockchain in their future operations.

Beyond the complexities of technological adaptation, introducing new services in electricity distribution requires additional resources and capabilities that are not part of the DSOs existing operations. DSOs are assessing their future needs to better understand how to ad apt. "From a capability perspective, we are now looking at the resources we have available and how these can support the challenges brought by the energy transition. Soon, we expect to have a clearer idea if our technical and human resources are adequate for the digitalization of electricity distribution." (representative DSO D)

Moving toward new business models requires detailed planning and consideration for the necessary investments and changes to be implemented. However, these plans are challenged by the need for DSOs to react to changes in the distribution network, such as the growth of connected distributed generation units. "The choice to pursue new business opportunities, and associated investments, faces a barrier related with the limited planning horizon. Plans are basically made as a reaction to new surges in connected distributed generation units." (representative DSO B). The need to continuously improve operational efficiency contributes also to the challenges of implementing strategic changes in the business model. This often 
results in preference being given to reactive measures such as outsourcing of activities and staff reductions. "Considering our challenging operational framework, we see outsourcing of business activities and staff reduction as options for the future." (representative DSO B). The characteristics of future business models can also be understood by considering the possible changes across core electricity distribution activities (see Table 6).

Table 6. Evolution of DSO activities (DSO A). Authors' elaboration from DSO A (2016).

\begin{tabular}{|c|c|c|c|}
\hline Activity & Traditional & Today & Future \\
\hline $\begin{array}{c}\text { Electricity } \\
\text { management }\end{array}$ & Load management & $\begin{array}{l}\text { Grid stability control with increasing } \\
\text { shares of distributed generation }\end{array}$ & Flexibility management \\
\hline Operation & Static load flow calculation & $\begin{array}{l}\text { Monitoring and control based on } \\
\text { additional measurements }\end{array}$ & Automated operational control \\
\hline $\begin{array}{c}\text { Asset } \\
\text { management }\end{array}$ & Standardized equipment & Integration of novel technologies & Operation and control of smart equipment \\
\hline Communication & $\begin{array}{l}\text { Exchange of aggregated values, } \\
\text { mostly for billing }\end{array}$ & $\begin{array}{l}\text { Immediate, transparent, and non- } \\
\text { discriminatory data transfer }\end{array}$ & Operation of a data platform \\
\hline $\begin{array}{c}\text { System } \\
\text { reliability }\end{array}$ & Local voltage quality & Introduction of ancillary services & $\begin{array}{l}\text { Provision of ancillary services via } \\
\text { distribution system }\end{array}$ \\
\hline
\end{tabular}

\subsection{Market design and regulation}

\subsubsection{Market structure}

Market structure is a relevant aspect when considering adapting market designs and existing regulatory frameworks. The electricity distribution industry across the EU presents a heterogeneous concentration, which is mostly the result of the historical and cultural perception of the interaction between communities and their electricity infrastructure. "DSO market concentration is mostly related to the fact that local communities wanted to have some control over their energy infrastructure. Therefore, patchy structures are a result of every community wanting to own their grid." (representative DSO A).

The attractiveness of electricity distribution as a business creates possibilities for changes in market structure. Municipalities are becoming increasingly interested in operating their local 
electricity distribution grids. This can result in a shift in ownership from larger, integrated DSOs that operate distribution grids through concessions with municipalities, to ownership by municipalities. "For instance, we have contracts with the municipalities for 20 years regarding the operation of their local grid, however, we note an increase in municipalities willingness to operate their grid by themselves, given that grid operation is a good business." (representative DSO A). This shift was observed in Hamburg, Germany when the incumbent utility Vattenfall lost the grid operation concession to a municipality (representative Research Centre A). This structural change was the result of a referendum for the re-municipalization of energy networks held in 2013 (Wagner and Berlo, 2015).

Changes in market structure can also result from different adaptation capabilities across different DSOs scales. In this context, larger DSOs seem to be better prepared to adapt to technological changes, given their ability to capture greater economies of scale because of their larger consumer base. "Larger DSOs companies have an easier time rolling out smart meters, and other smart grid related technology." (representative DSO D).

Electricity sector reforms impact also the distribution market structure. Market liberalization was introduced as a driver for more affordable, higher quality electricity services. However, having an integrated view of the electricity supply chain, which was a possibility in vertically integrated utilities, can also be beneficial in times of disruptive change in the electricity sector. When pushing for innovation it does help to look at the entire electricity supply chain. 


\subsubsection{Regulatory aspects}

The regulatory framework in each country was presented as important to incentivize DSOs in the rollout of new technologies. To this end, existing market designs focusing on operational efficiency improvements represent a sensible approach for a traditionalelectricity distribution industry. However, it is less compatible with a changing electricity sector in which new technologies are being integrated across the electricity supply chain, which impact electricity distribution. This hinders the engagement of DSOs in smart grid developments. "This is badnews for smart grid related projects that often reduce the operational efficiency and harm revenue collection capability. This regulatory approach creates barriers on the business strategy DSOs pursue. This results in a preference for grid expansion instead of smart grid investments, since a smart grid would increase the operational costs, where a grid expansion increases the capital costs and thus increase the efficiency factor." (representative DSO A). This insight highlights the importance to reevaluate and adjust how cost structures are regulated as distribution networks become smarter and integrate grater levels of distributed energy resources. Regulatory models that support innovation and the transition to smart grids must consider a new balance between operational expenditures (OPEX) and capital expenditures (CAPEX). For instance, managing and coordinating higher shares of distributed generation can result in increased OPEX while supporting CAPEX containment or deferment, which challenge the traditional CAPEX bias. Despite the importance of rethinking cost structures only Finland, France, Ireland, and the United Kingdom have implemented incentives for OPEX associated to innovation activities (Eurelectric, 2016).

Regarding the investment needs to adapt to a changing electricity sector it is important to highlight that financial resources are not a significant barrier; the real barrier is obtaining 
business plan approval. "For all these future activities we need to be able to get the money, but this is not difficult; what is difficult is obtaining an approved business model by the regulator for these investments." (representative DSO B). Efforts to adjust existing market design and regulations have benefited from the growing resources dedicated to advancing the energy transition. "The energy transition is supporting an increased attention into topics related to the changing role of DSOs." (representative DSO A).

While Germany and Portugal are lagging in terms of legislation mandating large-scale smart meter rollouts, consequently impacting the transition to smart grids, other EU member countries present more prominent outlooks. These differences across Member States are partly due to differences in innovation and adaptation support of each country's regulatory framework. In Germany, only a limited number of innovative projects are approved by the regulators for DSO development, whereas in Portugal a scheme of a $1.5 \%$ bonus to the rate of return was initially implemented. The regulatory frameworks in both Portugal and Germany exclude large-scale pilots or innovative technology rollouts, and are considered as presenting some degree of regulatory hurdles to innovation (Eurelectric, 2014). Concurrently, regulatory approaches implemented in Italy, Norway, and the United Kingdom, have been presented as best practices. The Italian regulator has been increasingly supporting the transition to smart grids since 2010 and has approved several pilot projects which receive a $2 \%$ bonus to the rate of return for a 12 -year period, providing DSOs with long term positive economic signals to engage in smart grids diffusion. The Norwegian regulator allows DSOs to recover innovation costs directly through tariffs, capped at $0.3 \%$ of their grid asset value. In the United Kingdom, the regulator has established an innovation stimulus package to support innovation. The package includes 'The Network Innovation 
Competition', in which DSOs compete for funding sources; the 'Network Innovation Alliance', through which DSOs receive an allowance based on their innovation strategy; and the 'Innovation Rollout Mechanism', which allows DSOs to request additional funding for innovative activities to be implemented in the regulatory period (Eurelectric, 2014, 2016).

In addition to regulatory aspects, the acceptance of new technologies also plays a critical role, such as smart meter acceptance by the households, which is closely related to data protection issues and cybersecurity concerns. The importance of these two aspects is widely accepted by the all interviewed experts and corroborated by the experiences in other countries. In the Netherlands, for instance as one of the early movers regarding smart metering, an insufficient consideration of privacy issues led to a significant loss in acceptance and delayed the rollout by several years (Hoenkamp et al., 2011). The UK, on the other hand, deliberately promoted their rollout and set up the Smart Metering Early Learning Project to investigate how to best engage customers in the rollout process. As a result, about $73 \%$ of smart meter owners would recommend it to others, with only $3 \%$ being skeptical. In this case, of those who still have an old meter, $48 \%$ would like to get a smart meter soon (Smart Energy GB, 2018).

\section{Synopsis of challenges and opportunities}

The insights obtained from the multi-stakeholder workshops are classified into challenges and opportunities for electricity distribution (companies' and system's/technologies') adaptation needs. This provides an updated perspective on what is hindering the adaptation of electricity distribution, as well as on which future opportunities are being considered. In terms of operations, technology, and asset management (see Table 7) challenges are perceived when it comes to both smart grid, and smart meter technologies, as well as legacy 
technologies. Future opportunities include flexibility management from distributed energy

resources, and more access to data as a new source of added value.

Table 7. Operations, technology, and asset management

\begin{tabular}{|c|c|c|}
\hline Topic & Challenges & Opportunities \\
\hline $\begin{array}{l}\text { Integration of } \\
\text { distributed energy } \\
\text { resources/distributed } \\
\text { generation }\end{array}$ & $\begin{array}{l}\text { - Operations at the medium and low voltage } \\
\text { segments of the grid. } \\
\text { - Surge of distributed generation in rural areas. } \\
\text { - Time and capital-intensive investments } \\
\text { required. } \\
\text { - Network stability. }\end{array}$ & - Increase system flexibility on low-voltage levels. \\
\hline $\begin{array}{c}\text { Operation and } \\
\text { maintenance }\end{array}$ & $\begin{array}{l}\text { - Peak loads, both in consumption and } \\
\text { production. }\end{array}$ & - Flexibility management. \\
\hline $\begin{array}{l}\text { Smart grid } \\
\text { technologies }\end{array}$ & $\begin{array}{l}\text { - Identify the best approach to integrate electric } \\
\text { mobility in electricity distribution grids. } \\
\text { - Regulatory framework and incentives for } \\
\text { electricity storage. } \\
\text { - Standardization of technologies for seamless } \\
\text { integration. }\end{array}$ & $\begin{array}{l}\text { - Electric mobility. } \\
\text { - Electricity storage. } \\
\text { - Smart metering. } \\
\text { - Distribution automation. } \\
\text { - Data-driven innovations. } \\
\text { - Partnerships with external data providers. }\end{array}$ \\
\hline $\begin{array}{l}\text { Smart meter } \\
\text { technologies }\end{array}$ & $\begin{array}{l}\text { - One-tariff system that hinders smart meters } \\
\text { potential to send economic signals. } \\
\text { - Uncertainty if smart meters are the best } \\
\text { technology for DSOs data needs. } \\
\text { - Increased complexity in data collection } \\
\text { - Cybersecurity and hacking concerns. } \\
\text { - Investment and cost allocation. } \\
\text { - Shorter life span of the technology. } \\
\text { - Standardization of communication protocols. }\end{array}$ & $\begin{array}{l}\text { - More information about the grid. } \\
\text { - Fault location capabilities. } \\
\text { - Observability. } \\
\text { - Network congestion management. }\end{array}$ \\
\hline Legacy technologies & $\begin{array}{l}\text { - Finding new places to build new transformer } \\
\text { stations. } \\
\text { - Obtaining permits for underground lines. }\end{array}$ & $\begin{array}{l}\text { - Low-cost legacy technologies that increase efficiency (Low } \\
\text { voltage transformers, standardized automated control devices) }\end{array}$ \\
\hline
\end{tabular}

Business models and organizational challenges (see Table 8) include strategic restructuring,

which has been pursued through demergers, creation of new companies to support

reallocation of assets and operations, and more recently mergers and acquisitions. While

innovation is being pursued and is considered a source of knowled ge for expanding service

offering, the inertia associated with DSOs traditional business culture challenges the adoption

of innovative technologies and hinders the possibilities for disruptive ideas to be considered.

Opportunities encompass integration and adaptation of distributed energy resources, and the

facilitation of data-intensive services. 


\begin{tabular}{|c|c|c|}
\hline Topic & Challenges & Opportunities \\
\hline $\begin{array}{c}\text { Business } \\
\text { restructuring } \\
\text { and mergers }\end{array}$ & $\begin{array}{l}\text { - Separating the more profitable from the less profitable } \\
\text { segments of the value chain. }\end{array}$ & $\begin{array}{l}\text { - Use mergers to boost scale-effects. } \\
\text { - Use partnerships to share development costs and risks. }\end{array}$ \\
\hline Innovation & $\begin{array}{l}\text { - Electricity sector historically tied to regulations and } \\
\text { legacy technologies. } \\
\text { - Innovation proposals are hard to pass through. } \\
\text { - Decision-makers adversity to disruptive ideas from } \\
\text { external stakeholders (e.g. from start-ups). }\end{array}$ & $\begin{array}{l}\text { - Advanced use of smart metering. } \\
\text { - Battery storage. } \\
\text { - Intelligent systems control. } \\
\text { - Virtual power plants. } \\
\text { - Integration of solar PV. } \\
\text { - Participation in R\&D projects with universities and external } \\
\text { partners at National and European level. } \\
\text { - Technology exploration and exploitation. } \\
\text { - Improve asset management. } \\
\text { - Business process improvement. } \\
\text { - Internal innovation initiatives. }\end{array}$ \\
\hline $\begin{array}{c}\text { Future } \\
\text { business } \\
\text { model }\end{array}$ & $\begin{array}{l}\text { Decision-makers adversity to using data for service } \\
\text { innovation. } \\
\text { - Understanding the technical and human resources } \\
\text { needed. } \\
\text { - Difficulty to establish future development plans, which } \\
\text { are mostly driven by distributed generation diffusion. }\end{array}$ & $\begin{array}{l}\text { - Expand service offering. } \\
\text { - Integrate new technologies. } \\
\text { - Develop new capabilities. } \\
\text { - Operate system flexibility. } \\
\text { - Provide ancillary services. } \\
\text { - Data-driven business models. } \\
\text { - Increase data collection through more sensors. } \\
\text { - Partner with external data providers for new service offerings. } \\
\text { - Outsource business activities. } \\
\text { - Staff reductions. }\end{array}$ \\
\hline
\end{tabular}

Regarding market design and regulation (see Table 9) challenges are associated with the

possible limitations of a liberalized market structure when considering disruptive changes.

Moreover, pursuing operational efficiency can act as a barrier on smart grid investments, as

well as result in job losses in the industry.

Table 9. Market design and regulation

\begin{tabular}{|c|c|c|}
\hline Topic & Challenges & Opportunities \\
\hline $\begin{array}{l}\text { Market } \\
\text { structure }\end{array}$ & $\begin{array}{l}\text { - Liberalized market structure can result in a siloed view of } \\
\text { the different segments of the supply chain. } \\
\text { - Focus on operational efficiency compromises smart grid } \\
\text { investments. }\end{array}$ & $\begin{array}{l}\text { - Considering the entire electricity sector supply chain, and how } \\
\text { innovation can improve it, beyond current market structures. }\end{array}$ \\
\hline $\begin{array}{l}\text { Regulatory } \\
\text { aspects }\end{array}$ & $\begin{array}{l}\text { - Continuous efficiency improvements } \\
\text { - Obtain regulatory approval for new business models. }\end{array}$ & $\begin{array}{l}\text { Increasingly engage in innovation activities that support smart } \\
\text { grid diffusion and create knowledge to adapt the regulatory } \\
\text { framework. }\end{array}$ \\
\hline
\end{tabular}

Further, we identified adaptation challenges that are perceived to impact DSOs differently, depending on their scale (see Figure 6). 


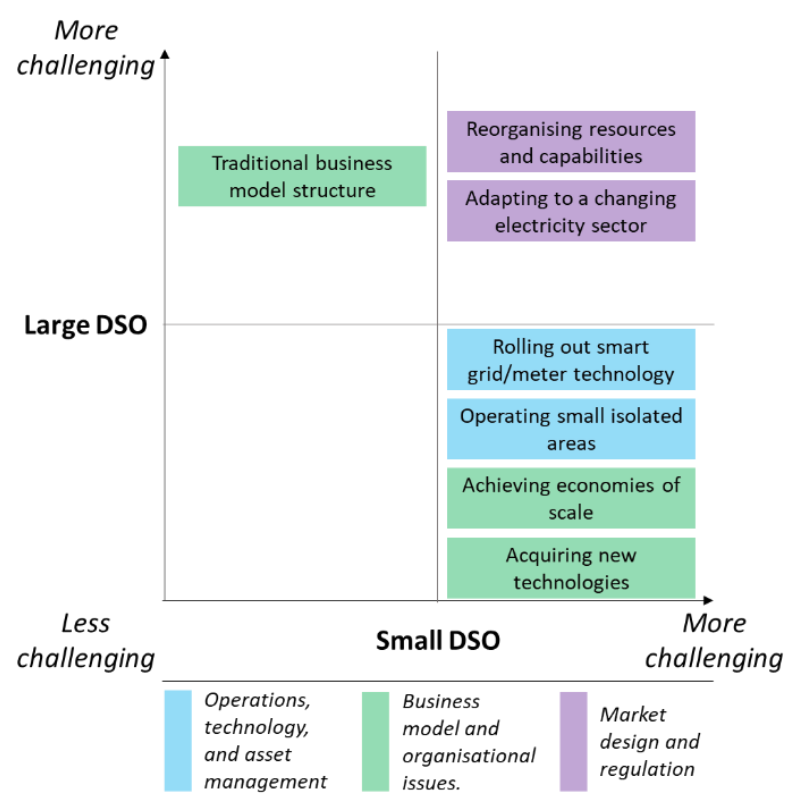

Figure 6. DSOs' scale and associated challenges.

\section{Conclusions and policy implications}

This study provides insights on challenges and opportunities for DSOs regarding technology, business models, and market design in the EU. Through a series of nine multi-stakeholder workshops in two representative EU Member States, Germany and Portugal, we collected qualitative up-to-date perspectives on how DSOs are facing and accommodating the shift to a smarter, more decentralized, and sustainable electricity sector. As the discussion on the digitalization of the electricity system increase, our findings reveal uncertainty regarding the value of full-scale rollouts of smart meters by DSOs. Policy makers should consider how this influences future expectations regarding large-scale diffusion of smart metering technology and should ensure that all potential benefits actually become exploited.

Adapting operations for the provision or facilitation of these new value-added services, such as flexibility management, is considered a promising opportunity. However, we observe a corporate culture with high levels of inertia to change. Future policies should consider the impacts of inertia to change in the deployment of innovative technologies and adoption of 
new business processes. Evolving toward smart grid technologies and processes can be challenging with a regulatory framework focused on continuous improvement of operational efficiency. Our insights also indicate that while operational efficiency is important, it may result in job losses in the quest for cost reductions, as well as motivate outsourcing of core business activities, leading to loss of internal knowledge and technical capabilities. Policy makers should consider these impacts when designing regulation to support smart grid investments and capability development by DSOs.

The results further provide a recent guiding reference on the challenges and opportunities impacting the electricity distribution industry in the EU, helping to pave the way for future research and considerations. Other countries are well advised to learn from experiences made in the investigated countries. In Portugal, the DSOs agreed with the regulator on a voluntary rollout without a legislative mandate and with the primary goal of value maximization. In Germany, on the other hand, the economic incentives for DSOs were apparently insufficient to ensure a quick diffusion on their own. Furthermore, the data protection and cybersecurity requirements have not yet been finalized. This is problematic both because it does not really contribute to dispel concerns and as an additional hurdle preventing a quick rollout even after a law mandating the general rollout-process has been enacted. Future work includes collecting more insights to understand how existing policies contribute to more adaptable DSOs across the EU, and DSOs' capabilities in delivering new business models. 


\section{Acknowledgements}

The authors acknowledge the Portuguese National Foundation for Science and Technology (FCT) for supporting this work through the grant PD/BD/105841/2014, funded through the POPH/FSE. Additionally, this work has been supported by FCT under project grant: UID/MULTI/00308/2013, SAICTPAC/0004/2015-POCI-01-0145-FEDER-016434, and POCI-010145-FEDER-029820 as well as by the Energy for Sustainability Initiative of the University of Coimbra. The workshops were financially supported by the German Academic Exchange Service (DAAD) and the Council of Rectors of Portuguese Universities (CRUP) under the project "The Electricity Sector Transition - Transnational Experiences from DSOs and Cooperatives".

\section{References}

ACER and CEER, 2017. The Role of the DSO. Agency for the Cooperation of Energy Regulators (ACER) and Council of European Energy Regulators (CEER). Brussels.

Aitzhan, N., Svetinovic, D., 2016. Security and Privacy in Decentralized Energy Trading through Multi-signatures, Blockchain and Anonymous Messaging Streams. IEEE Trans. Dependable Secur. Comput. 5971, 1-1. doi:10.1109/TDSC.2016.2616861

Anaya, K.L., Pollitt, M.G., 2015. Integrating distributed generation: Regulation and trends in three leading countries. Energy Policy 85, 475-486. doi:10.1016/j.enpol.2015.04.017

Bijker, W.E., Hughes, T.P., Pinch, T., 2012. The Social Construction of Technological Systems. MIT Press, Cambridge, MA.

BMWi, 2014. Modern electricity distribution netwokrs for Germany. Federal Ministry for Economic Affairs and Energy (BMWi, Bundesministerium für Wirtschaft und Energie). Berlin.

BMWi, 2013. Cost-benefit analysis for the comprehensive use of smart metering systems. Federal Ministry for Economic Affairs and Energy (BMWi, Bundesministerium für Wirtschaft und Energie). Berlin.

BNetzA, 2014. Incentive regulation of gas and electricity network operators. Federal Network Agency (BNetzA, Bundesnetzagentur). Berlin.

Bolton, R., Foxon, T.J., 2015. Infrastructure transformation as a socio-technical process - Implications for the governance of energy distribution networks in the UK. Technol. Forecast. Soc. Change 90, 538-550. doi:10.1016/j.techfore.2014.02.017

Cambini, C., Meletiou, A., Bompard, E., Masera, M., 2016. Market and regulatory factors influencing smart-grid investment in Europe: Evidence from pilot projects and implications for reform. Util. Policy 40, 36-47. doi:10.1016/j.jup.2016.03.003

Castro, N., Dantas, G., 2017. Distributed Generation: International experiences and comparative analyses. PUBLIT, Rio de Janeiro.

CEER, 2015. The Future Role of DSOs. A CEER Conclusions Paper. Council of European Energy Regulators (CEER). Brussels.

CEER, 2014. The Future Role of DSOs. A CEER Public Consultation Paper. Council of European Energy Regulators (CEER). Brussels.

Council of the European Union, 2017a. Proposal for a regulation of the European Parliament and of the Council on the internal market for electricity. Council of the European Union. Brussels.

Council of the European Union, 2017b. Proposal for a directive of the European Parliament and of the Council on the internal market for electricity - Annex I. Council of the European Union. Brussels.

Council of the European Union, 2017c. Proposal for a directive of the European Parliament and of the Council on the internal market for electricity. Council of the European Union. Brussels.

Dallinger, D., Gerda, S., Wietschel, M., 2013. Integration of intermittent renewable power supply using grid-connected vehicles - A 2030 case study for California and Germany. Appl. Energy 104, 666-682. doi:10.1016/j.apenergy.2012.10.065

Damsgaard, N., Papaefthymiou, G., Grave, K., Helbrink, J., Giordano, V., Gentili, P., 2015. Study on the effective integration of Distributed Energy Resources for providing flexibility to the electricity system. Final report to the European Commission.

Davies, A., 1996. Innovation in Large Technical Systems: The Case of Telecommunications. Ind. Corp. Chang. 5, 11431180. doi:10.1093/icc/5.4.1143

Depuru, S.S.S.R., Wang, L., Devabhaktuni, V., 2011. Smart meters for power grid: Challenges, issues, advantages and status. Renew. Sustain. Energy Rev. 15, 2736-2742. doi:10.1016/j.rser.2011.02.039 
Deutscher Bundestag, 2007. Regulation on the adoption and amendment of legislation in the field of energy regulation. German Federal Parlament (Deutscher Bundestag). Berlin.

Dobre, C.C., Vinke-de Kruijf, J., Moretto, L., Ranzato, M., 2018. Stormwater management in transition: The influence of technical and governance attributes in the case of Brussels, Belgium. Environ. Sci. Policy 85, 1-10. doi:10.1016/j.envsci.2018.03.015

Droste-Franke, B., Klüser, R., Noll, T., 2012. Balancing renewable electricity. Energy storage, demand side management, and network extension from an interdisciplinary perspective. Springer (Ethics of science and technology assessment, v. 40), Heidelberg, New York.

Dul, J., Hak, T., 2008. Case Study Methodology in Business Research. Butterworth-Heinemann, Burlington, MA.

E.ON, 2018. Creating the future of energy. Berlin.

E.ON and RWE, 2018. E.ON and RWE: two European energy companies focus their activities. Berlin.

EAFO, 2018. Electric vehicle statistics EU 28.

EEA, 2016. Electric Vehicles in Europe, European Environment Agency (EEA). Copenhagen.

Electricity Distribution System Operator A, 2016. Internal DSO documentation.

Eurelectric, 2016. Innovation incentives for DSOs - a must in the new energy market development. Eurelectric. Brussels.

Eurelectric, 2014. Electricity Distribution Investments: What Regulatory Framework Do We Need? Eurelectric. Brussels.

Eurelectric, 2013. Power distribution in Europe - Facts and figures. Eurelectric. Brussels.

Eurelectric, 2010. The Role of Distribution System Operators (DSOs) as Information Hubs. Eurelectric. Brussels.

European Commission, 2017a. Proposal for a directive of the European Parliament and of the Council on the internal market for electricity. European Commission. Brussels.

European Commission, 2017b. Smart Metering deployment in the European Union. European Commission. Brussels.

European Commission, 2016a. Clean Energy for All Europeans. European Commission. Brussels.

European Commission, 2016b. Evaluation Report covering the Evaluation of the EU's regulatory framework for electricity market design and consumer protection in the fields of electricity and gas. European Commission. Brussels.

European Commission, 2015. A Framework Strategy for a Resilient Energy Union with a Forward-Looking Climate Change Policy. European Commission. Brussels.

European Commission, 2014a. Cost-benefit analyses \& state of play of smart metering deployment in the EU-27. European Commission. Brussels.

European Commission, 2014b. Benchmarking smart metering deployment in the EU-27 with a focus on electricity. European Commission. Brussels.

European Commission, 2012. Commission recommendation on preparations for the roll-out of smart metering systems. European Commission. Brussels.

European Commission, 2010. Energy 2020 A strategy for competitive, sustainable and secure energy., European Commission. Brussels.

European Commission, 2009a. Directive 2009/72/EC of the European Parliament and of the Council of 13 July 2009 concerning common rules for the internal market in electricity and repealing Directive 2003/54/EC. European Commission. Brussels.

European Commission, 2009b. Directive 2009/28/EC of the European Parliament and of the Council of 23 April 2009 on the promotion of the use of energy from renewable sources and amending and subsequently repealing Directives 2001/77/EC and 2003/30/EC. European Commission. Brussels.

Eurostat, 2018. Renewable Energy Shares in Europe. Brussels.

Ewertsson, L., Ingelstam, L., 2004. Large Technical Systems: a Multidisciplinary Research Tradition, Systems approach and their application. Kluwer Academic Publishers. doi:- 10.1007/1-4020-2370-7_15

Farla, J., Markard, J., Raven, R., Coenen, L., 2012. Sustainability transitions in the making: A closer look at actors, strategies and resources. Technol. Forecast. Soc. Change 79, 991-998. doi:10.1016/j.techfore.2012.02.001

Gangale, F., Vasiljevska, J., Covrig, C.F., Mengolini, A., Fulli, G., 2017. Smart grid projects outlook 2017 Facts, figures and trends in Europe. doi:10.2760/15583 
Geels, F.W., 2014. Reconceptualising the co-evolution of firms-in-industries and their environments: Developing an interdisciplinary Triple Embeddedness Framework. Res. Policy 43, 261-277. doi:10.1016/j.respol.2013.10.006

Geels, F.W., 2002. Technological transitions as evolutionary reconfiguration processes: a multi-level perspective and a casestudy. Res. Policy 31, 1257-1274. doi:10.1016/S0048-7333(02)00062-8

Giordano, V., Flavia, G., Gianluca, F., Manuel Sanchez, J., 2011. Smart Grid projects in Europe: lessons learned and current developments. Peten. doi:10.2790/32946

Giordano, V., Fulli, G., 2011. A business case for Smart Grid technologies: A systemic perspective. Energy Policy 40, 252259. doi:10.1016/j.enpol.2011.09.066

Giordano, V., Meletiou, A., Covrig, C.F., Mengolini, A., Ardelean, M., Fulli, G., Sanches Jimenez, M., Fillou, C., 2013. Smart Grids Projects in Europe: Lessons Learned and Current Developments. JRC Sci. Policy Reports 1-142. doi:10.1007/s 13398-014-0173-7.2

Hall, S., Foxon, T.J., 2014. Values in the Smart Grid: The co-evolving political economy of smart distribution. Energy Policy 74, 600-609. doi:10.1016/j.enpol.2014.08.018

Hasenöhrl, U., 2018. Rural electrification in the British Empire. Hist. Retail. Consum. 4, 10-27. doi:10.1080/2373518X.2018.1436220

Helms, T., 2016. Asset transformation and the challenges to servitize a utility business model. Energy Policy 91, 98-112. doi:10.1016/j.enpol.2015.12.046

Hoenkamp, R., Huitema, G., De Moor-van Vugt, A., 2011. The Neglected Consumer: The Case of the Smart Meter Rollout in the Netherlands. Renew. Energy Law Policy Rev. 269-282. doi:10.2139/ssrn.1917455

Hughes, T.P., 1987. The Evolution of Large Technological Systems, in: The Social Construction of Technological Systems - New Directions in the Sociology and History of Technology. The MIT Press, Massachusetts.

Hughes, T.P., 1983. Networks of Power: Electrifiation in Western Society 1880-1930. The Johns Hopkins University Press, Baltimore.

ICCS-NTUA, AF Mercados EMI, 2015. Study on cost benefit analysis of Smart Metering Systems in EU Member States. Athens, Madrid.

Ipakchi, A., Albuyeh, F., 2009. Grid of the future. IEEE Power Energy Mag. 7, 52-62. doi:10.1109/MPE.2008.931384

Kabalci, Y., 2016. A survey on smart metering and smart grid communication. Renew. Sustain. Energy Rev. 57, $302-318$. doi:10.1016/j.rser.2015.12.114

Kindon, S., Pain, R., Kesby, M., 2007. Participatory action research aproaches and methods, Human Geography.

Knirsch, F., Unterweger, A., Eibl, G., Engel, D., 2018. Sustainable Cloud and Energy Services. doi:10.1007/978-3-31962238-5

Krishnamurti, T., Schwartz, D., Davis, A., Fischhoff, B., de Bruin, W.B., Lave, L., Wang, J., 2012. Preparing for smart grid technologies: A behavioral decision research approach to understanding consumer expectations about smart meters. Energy Policy 41, 790-797. doi:10.1016/j.enpol.2011.11.047

Krivokapic-Skoko, B., O'neill, G., 2011. Beyond the qualitative-quantitative distinction: Some innovative methods for business and management research. Int. J. Mult. Res. Approaches 5, 290-300. doi:10.5172/mra.2011.5.3.290

Lavrijssen, S., Marhold, A., Trias, A., 2016. The Changing World of the DSO in a Smart Energy System Environment: Key Issues and Policy Recommendations. Cent. Regul. Eur. 98.

Lopes, J.A.P., Hatziargyriou, N., Mutale, J., Djapic, P., Jenkins, N., 2007. Integrating distributed generation into electric power systems: A review of drivers, challenges and opportunities. Electr. Power Syst. Res. 77, 1189-1203. doi:10.1016/j.epsr.2006.08.016

Mahroum, S., Bell, S., Al-Saleh, Y., Yassin, N., 2016. Towards an Effective Multi-Stakeholder Consultation Process: Applying the Imagine Method in Context of Abu Dhabi's Education Policy. Syst. Pract. Action Res. 29, $335-353$. doi:10.1007/s11213-016-9367-6

Markard, J., Truffer, B., 2006. Innovation processes in large technical systems: Market liberalization as a driver for radical change? Res. Policy 35, 609-625. doi:10.1016/j.respol.2006.02.008

Martinot, E., 2016. Grid Integration of Renewable Energy: Flexibility, Innovation, and Experience. Annu. Rev. Environ. Resour. 41, 223-251.

McHenry, M.P., 2013. Technical and governance considerations for advanced metering infrastructure/smart meters: 
Technology, security, uncertainty, costs, benefits, and risks. Energy Policy 59, 834-842. doi:10.1016/j.enpol.2013.04.048

Mengelkamp, E., Gärttner, J., Rock, K., Kessler, S., Orsini, L., Weinhardt, C., 2017a. Designing microgrid energy markets. A case study: The Brooklyn Microgrid. Appl. Energy. doi:10.1016/j.apenergy.2017.06.054

Mengelkamp, E., Notheisen, B., Beer, C., Dauer, D., Weinhardt, C., 2017b. A blockchain-based smart grid: towards sustainable local energy markets. Comput. Sci. - Res. Dev. 1-8. doi:10.1007/s00450-017-0360-9

My Smart Energy, 2018a. Germany country status 2018.

My Smart Energy, 2018b. Portugal country report 2018.

Nisar, A., Ruiz, F., Palacios, M., 2013. Organisational learning, strategic rigidity and technology adoption: Implications for electric utilities and renewable energy firms. Renew. Sustain. Energy Rev. 22, 438-445. doi:10.1016/j.rser.2013.01.039

Palensky, P., Dietrich, D., 2011. Demand Side Management: Demand Response, Intelligent Energy Systems, and Smart Loads. IEEE Trans. Ind. Informatics 7, 381-388. doi:10.1109/TII.2011.2158841

Palm, J., Gustafsson, S., 2018. Barriers to and enablers of district cooling expansion in Sweden. J. Clean. Prod. 172, 39-45. doi:10.1016/j.jclepro.2017.10.141

Pepermans, G., Driesen, J., Haeseldonckx, D., Belmans, R., D’haeseleer, W., 2005. Distributed generation: definition, benefits and issues. Energy Policy 33, 787-798. doi:10.1016/j.enpol.2003.10.004

Pereira, G.I., da Silva, P.P., Soule, D., 2018a. Policy-adaptation for a smarter and more sustainable EU electricity distribution industry: a foresight analysis. Environ. Dev. Sustain. 1-37. doi:10.1007/s 10668-018-0119-x

Pereira, G.I., Pereira da Silva, P., Soule, D., 2018b. Assessment of electricity distribution business model and market design alternatives: Evidence for policy design. Energy Environ. 0958305X1875824. doi:10.1177/0958305X18758248

Pereira, G.I., Silva, P.P., 2017. The smart grid and distributed generation nexus, in: Castro, N. De, Dantas, G. (Eds.), Distributed Generation: International Experiences and Comparative Analyses. PUBLIT, Rio de Janeiro.

Prettico, G., Gandale, F., Mengolini, A., Lucas, A., Fulli, G., 2016. Distribution system operators observatory: From European electricity distribution systems to represntative distribution networks. doi:10.2790/701791

Pudjianto, D., Ramsay, C., Strbac, G., 2007. Virtual power plant and system integration of distributed energy resources. IET Renew. Power Gener. 1, 10. doi:10.1049/iet-rpg:20060023

Reddy, K.S., Kumar, M., Mallick, T.K., Sharon, H., Lokeswaran, S., 2014. A review of Integration, Control, Communication and Metering (ICCM) of renewable energy based smart grid. Renew. Sustain. Energy Rev. 38, $180-192$. doi:10.1016/j.rser.2014.05.049

Reuver, M., Lei, T., Lukszo, Z., 2016. How should grid operators govern smart grid innovation projects? An embedded case study approach. Energy Policy 97, 628-635. doi:10.1016/j.enpol.2016.07.011

Ringel, M., Knodt, M., 2018. The governance of the European Energy Union: Efficiency, effectiveness and acceptance of the Winter Package 2016. Energy Policy 112, 209-220. doi:10.1016/j.enpol.2017.09.047

Rip, A., Kemp, R., 1998. Technological change, in: Rayner, S., Malone, E.L. (Eds.), Human Choice and Climate Change. Battelle Press, Columbus, pp. 327-399.

Ruiz-Romero, S., Colmenar-Santos, A., Mur-Pérez, F., López-Rey, Á., 2014. Integration of distributed generation in the power distribution network: The need for smart grid control systems, communication and equipment for a smart city — Use cases. Renew. Sustain. Energy Rev. 38, 223-234. doi:10.1016/j.rser.2014.05.082

Schot, J., Geels, F.W., 2008. Strategic niche management and sustainable innovation journeys: theory, findings, research agenda, and policy. Technol. Anal. Strateg. Manag. 20, 537-554. doi:10.1080/09537320802292651

Schut, M., Klerkx, L., Rodenburg, J., Kayeke, J., Hinnou, L.C., Raboanarielina, C.M., Adegbola, P.Y., van Ast, A., Bastiaans, L., 2015. RAAIS: Rapid Appraisal of Agricultural Innovation Systems (Part I). A diagnostic tool for integrated analysis of complex problems and innovation capacity. Agric. Syst. 132, 1-11. doi:10.1016/j.agsy.2014.08.009

Sharma, K., Saini, L.M., 2015. Performance analysis of smart metering for smart grid: An overview. Renew. Sustain. Energy Rev. 49, 720-735. doi:10.1016/j.rser.2015.04.170

Shomali, A., Pinkse, J., 2016. The consequences of smart grids for the business model of electricity firms. J. Clean. Prod. 112, 3830-3841. doi:10.1016/j.jclepro.2015.07.078

Siano, P., 2014. Demand response and smart grids-A survey. Renew. Sustain. Energy Rev. 30, $461-478$. doi:10.1016/j.rser.2013.10.022 
Smart Energy GB, 2018. Smart energy outlook.

Sovacool, B.K., Lovell, K., Ting, M.B., 2018. Reconfiguration, Contestation, and Decline. Sci. Technol. Hum. Values 016224391876807. doi:10.1177/0162243918768074

Sreejesh, S., Mohapatra, S., Anusree, M.R., 2014. Business Research Methods. Springer International Publishing, Cham. doi:10.1007/978-3-319-00539-3

Truffer, B., Störmer, E., Maurer, M., Ruef, A., 2010. Local strategic planning processes and sustainability transitions in infrastructure sectors. Environ. Policy Gov. 20, 258-269. doi:10.1002/eet.550

Turnheim, B., Berkhout, F., Geels, F., Hof, A., McMeekin, A., Nykvist, B., van Vuuren, D., 2015. Evaluating sustainability transitions pathways: Bridging analytical approaches to address governance challenges. Glob. Environ. Chang. 35, 239253. doi:10.1016/j.gloenvcha.2015.08.010

Veldman, E., Gibescu, M., Slootweg, H.J.G., Kling, W.L., 2013. Scenario-based modelling of future residential electricity demands and assessing their impact on distribution grids. Energy Policy 56, 233-247. doi:10.1016/j.enpol.2012.12.078

Vleuten, E. Van Der, 2018. Radical change and deep transitions : Lessons from Europe' s infrastructure transition 1815 2015. Environ. Innov. Soc. Transitions 1-11. doi:10.1016/j.eist.2017.12.004

Wagner, O., Berlo, K., 2015. The wave of remunicipalisation of energy networks and supply in Germany -the establishment of 72 new municipal power utilities. ECEE Summer Study Proc. 559-569.

Wood, J., Funk, S., 2017. Can demand response help reduce future distribution grid investments? An economic study of peak shaving in the Norwegian distribution grid: SEMIAH pilot in Engene, Sørlandet (Southern Norway). Norwegian School of Economics Centre of Energy, Natural Resources and the Environment.

Yan, Y., Qian, Y., Sharif, H., Tipper, D., 2013. A Survey on Smart Grid Communication Infrastructures: Motivations, Requirements and Challenges. IEEE Commun. Surv. tutorials 15, 5-20.

Yin, R.K., 2011. Qualitative Research from Start to Finish. The Guilford Press, New York.

Zank, S., 2018. European Utilities From demergers to M\&A: E.ON and RWE set to transform European energy sector. Berlin.

Zank, S., Guerin, A., Müller, O., 2016. European integrated utilities from headwinds to tailwinds. Berlin. 